\title{
Microstructural deformation mechanisms of unsaturated granular soils
}

\author{
J. A. Gili and E. E. Alonso*,† \\ Department of Geotechnical Engineering and Geosciences, Universitat Politècnica de Catalunya, Gran Capitán s/n, \\ Módulo D-2, Barcelona 08034, Spain
}

\begin{abstract}
SUMMARY
A discrete model for unsaturated granular soils has been developed. Three discrete entities have been defined: particles, water menisci and pores. Local interaction forces and water transfer mechanisms have been integrated into a model through the appropriate equilibrium and balance equations. The results of several numerical tests using this model have been described and discussed. Simulations include wetting and drying under load tests, the application of suction cycles and the effect of a deviatoric stress ratio on wetting-induced collapse. The model reacts just as true granular soil samples behave in laboratory tests. The model provides a new insight into the internal mechanisms leading to large-scale features of behaviour such as wetting-induced collapse or the increase in soil strength provided by suction. The paper also stresses that matric suction changes acting on a granular structure are capable of explaining most of the macroscopic features of stress-strain behaviour. Copyright (C) 2002 John Wiley \& Sons, Ltd.
\end{abstract}

KEY WORDS: unsaturated soils; granular soil; micromechanics; distinct element method; numerical tests; suction

\section{INTRODUCTION}

Basic interaction mechanisms among soil particles have been investigated in the past by means of the Distinct Element Method [1,2]. Initial models, based on disc-shaped particles, have evolved and have led to numerous studies dealing with the micromechanics of soils [3] and other large-scale problems such as flow and impact analysis involving granular media [4-9]. This tool has explained the mechanisms of stress transfer through grain contacts and has helped also to disclose the nature of some basic stress-strain features such as the generation of shear bands [10] or the underlying phenomena behind liquefaction [11]. All the studies mentioned refer to dry (or saturated) soils and therefore the 'discrete element' which is defined in the computational model is the actual soil particle.

In an unsaturated granular material, there are additional new elements or internal entities, which should be defined in order to understand properly the soil behaviour. Menisci (Figure 1(a)

\footnotetext{
*Correspondence to: E. E. Alonso, Department of Geotechnical Engineering and Geosciences, Universitat Politècnica de Catalunya, Gran Capitán s/n, Módulo D-2, Barcelona 08034, Spain

†E-mail: eduardo.alonso@upc.es
} 
and 1(b)) introduce new forces at the particle contacts, which can be quantified through capillary theory. The shape of menisci is linked to the local geometry of the contact and to the mass of water existing at a given contact. However, the local mass of water associated with a particular contact may change as a result of water transfer processes both in liquid and vapour phases. These transfer processes take place along particle surfaces and also across the soil pores whenever a change in boundary conditions is produced. A typical situation arises when a given soil structure holding a given mass of water, in local equilibrium at each particle-to-particle contact, is subjected to an external change of water suction. This change will result in water transfer mechanisms leading to a new equilibrium state resulting in new geometrical configurations for the menisci and therefore, in new forces acting at the contacts, which may eventually lead to changes in the overall particle configuration.

It turns out that the unsaturated granular soil, in which fluid transfer and mechanical effects are considered, may be defined through three types of 'discrete elements': particles, menisci and pores. By formulating the interactions among them in a manner that will be outlined later, a fairly general tool to investigate the fundamental behaviour of unsaturated granular soils may be developed. A numerical tool of this kind may help to investigate, from a basic perspective, the behaviour of unsaturated soils under combined changes of stress and suction. Specific issues which may be examined include the microstructural mechanisms involved in collapse phenomena, the effect of deviatoric stresses on volume change induced by suction changes, the effect of suction on strength or the influence of suction cycles on soil deformation. These questions, which address relevant aspects of constitutive model development, are currently being
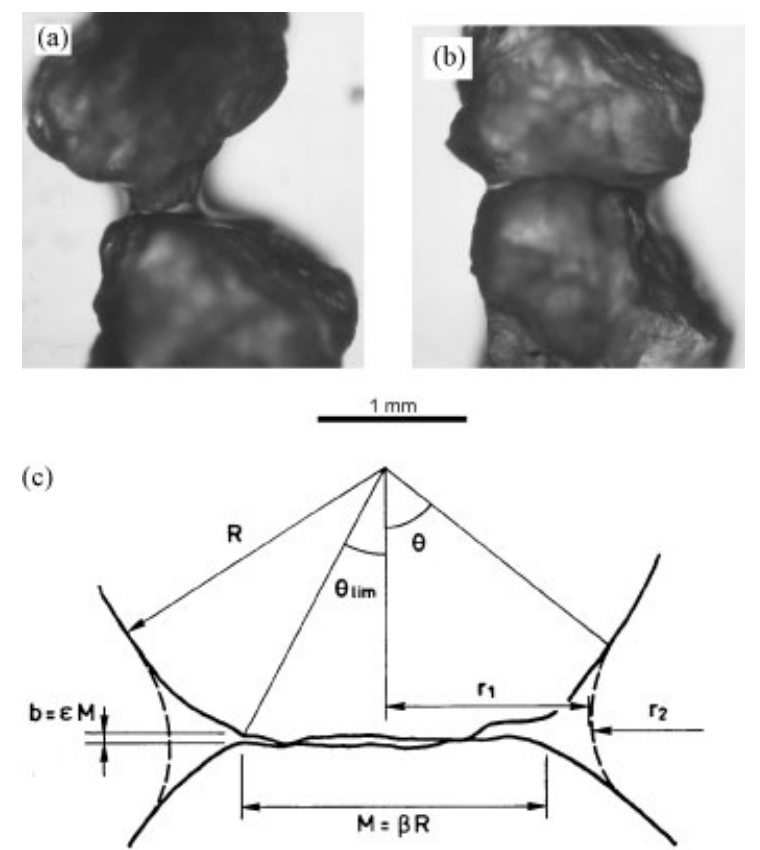

Figure 1. (a,b) Photograph of menisci at the contact between sand particles. (c) Geometry of a planar contact between particles. 
investigated by means of suction-controlled experiments in the laboratory. It is believed, however, that micromechanical modelling provides complementary information, which may be used to validate, or otherwise, some key hypothesis adopted in elastoplastic constitutive models for unsaturated soils. In addition, the tool developed provides an insight into basic mechanisms, which is very difficult to obtain in laboratory tests. It may also be used to perform numerical experiments at a reduced effort.

This paper presents a micromechanically based coupled flow and mechanical model for unsaturated granular soils made of spherical particles. Flow and phase change formulations will be described in some detail. However, the paper will concentrate on mechanical effects (force distributions and stress-strain behaviour under different stress paths involving histories of stress and suction changes). The role of suction in the selected numerical experiments solved will be highlighted. The model calculations will be compared in some cases with some experimental results in order to add value to the discussion.

The model presented in the paper is essentially two-dimensional (2D). However, particles are represented as spheres instead of discs in order to preserve the three-dimensional (3D) nature of contacts. This is important if the local interaction forces induced by water menisci at grain contacts are to be evaluated realistically. The model, therefore, handles spheres whose centres are restricted to move in a given plane. This model may be an acceptable approximation to granular soils such as medium to fine sands and silts (capillary effects in coarse sands and gravels have a negligible effect on mechanical behaviour). Clays, with its plate-like particles, are far from the ideal granular structure considered in this work. However, in many clayey soils, clay particles aggregate in larger units which are comparable, in size, to silt or fine sand particles [18]. This type of microstructure, which is specially marked in compacted clayey soils dry of optimum and in some natural clays of open structure, explains some features of the behaviour of these clays (such as the collapse upon wetting). This is also a behaviour typically found in unsaturated fine grained granular soils. It is believed, therefore, that the granular computer model developed in this work may provide a useful fundamental interpretation to a wide class of unsaturated soils characterized by a granular structure.

\section{GEOMETRY AND CAPILLARY FORCES IN AN IDEAL UNSATURATED GRANULAR SOIL}

An ideal soil integrated by spherical particles of three different diameters will be considered. Particle centres will be restricted to move in a given plane. Water will be distributed as films of molecules covering the particle surfaces and around particle-to-particle contacts, where water will form a capillary meniscus. Figure 2 shows a set of particles (or 'sample') in a circular configuration obtained through a random generation procedure. Numerical tests, discussed later, take this configuration as the initial state of the sample. The grains indicated in Figure 2 are true spheres whose diameters are 3,4 and $5 \times 10^{-2} \mathrm{~mm}$. From a grain size point of view, the soil is therefore a uniform silt.

Contacts between grains are three-dimensional in nature and water menisci have a toroidal shape as shown in Figure 3. Note that a contact is not necessarily defined by two tangent spheres (strict contact). Both the cases of 'quasi-contact' and 'over-contact', defined in Figure 3, which may accommodate a water meniscus, are also included in the model. The type of contact is 


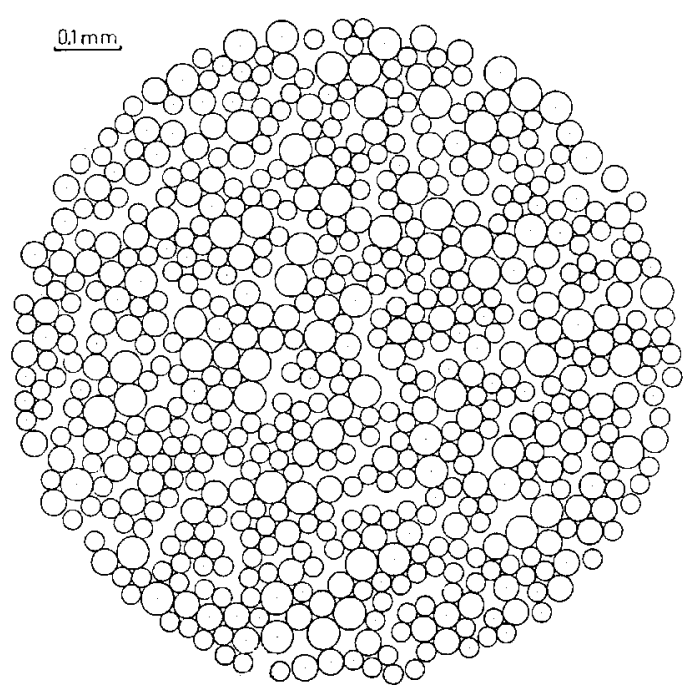

Figure 2. Sample of 592 spherical particles used in the paper to perform numerical tests.

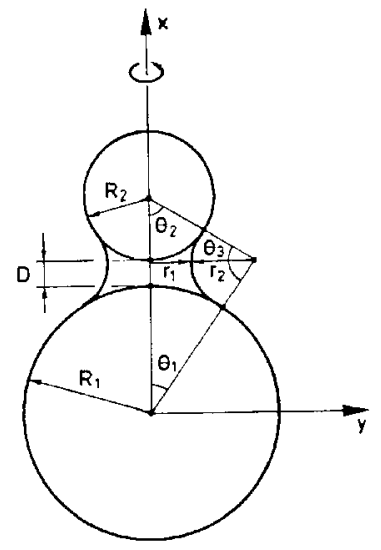

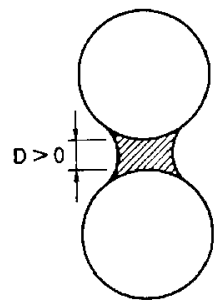

(a)

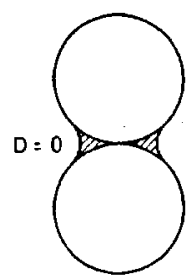

(b)

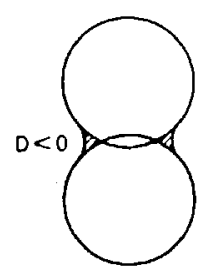

(c)

Figure 3. Geometry of a toroidal meniscus. Generalized case. (a) Quasi-contact, (b) Strict contact and (c) Over-contact (dimensions exaggerated). 
described by the distance parameter $D$ (Figure 3). The volume of water in a contact is defined by $D$ and the wetting angles $\theta_{1}$ and $\theta_{2}$.

Within the hypothesis that a meniscus is properly represented by a toroidal surface, tangent to the spheres, it is possible to derive analytic expressions for the hydraulic interaction forces among particles using the Laplace equation as a starting point:

$$
s=p_{\mathrm{a}}-p_{\mathrm{w}}=\sigma\left(\frac{1}{r_{1}}+\frac{1}{r_{2}}\right)
$$

where $p_{\mathrm{a}}$ is the air pressure in the open pores, $p_{\mathrm{w}}$ is the water pressure inside the meniscus, $\sigma$ is the surface tension and $r_{1}, r_{2}$ are the two curvature radii, which define the toroidal surface and $s$ is the matric or capillary suction.

For the case of two equal spheres (radius, $R$, and wetting angle, $\theta$ ) the attraction force is plotted in Figure 4 as a function of wetting angle [12]. For an infinite suction $(\theta \rightarrow 0)$ and for the case of strict contact, the capillary force has a finite value:

$$
F_{\mathrm{w}}=2 \pi \sigma R
$$

The same limiting force is derived for an over-contact $(D<0)$ as shown in Figure 4. However, for quasi-contact conditions, the meniscus eventually vanishes as suction increases ( $\theta$ decreases) and the interaction force becomes zero for a limiting wetting angle.

These ideal conditions change substantially when the contact becomes a flat surface as illustrated in Figure 1(b). The contact between two particles becomes now a narrow slot characterized in Figure 1(c) by a thickness $b$ and a diameter $M=\beta R$. Interaction forces between the adjacent particles may now increase dramatically if compared with the forces plotted in Figure 4 . Figure 5 shows an example of computed attraction forces, $F_{\mathrm{w}}$, through a contact slot characterized by $\beta=0.5$ and $\varepsilon=0.02$ (thickness parameter $\varepsilon$ is defined in Figure 1(c)). $F_{\mathrm{w}}$ will only decrease when suction becomes high enough to empty the slot. Air entry into the slot will now be governed by the specific geometry of the slot itself. Figure 5 also points out that the interaction forces between planar particles (such as clay platelets) may become very high. In this

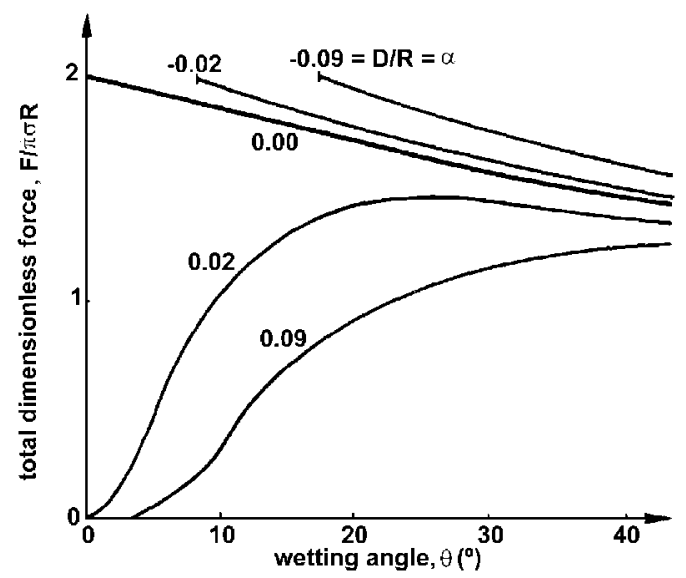

Figure 4. Attraction force due to a meniscus between two neighbouring particles of equal radius. $D$ is the size of the gap (see Figure 3). 


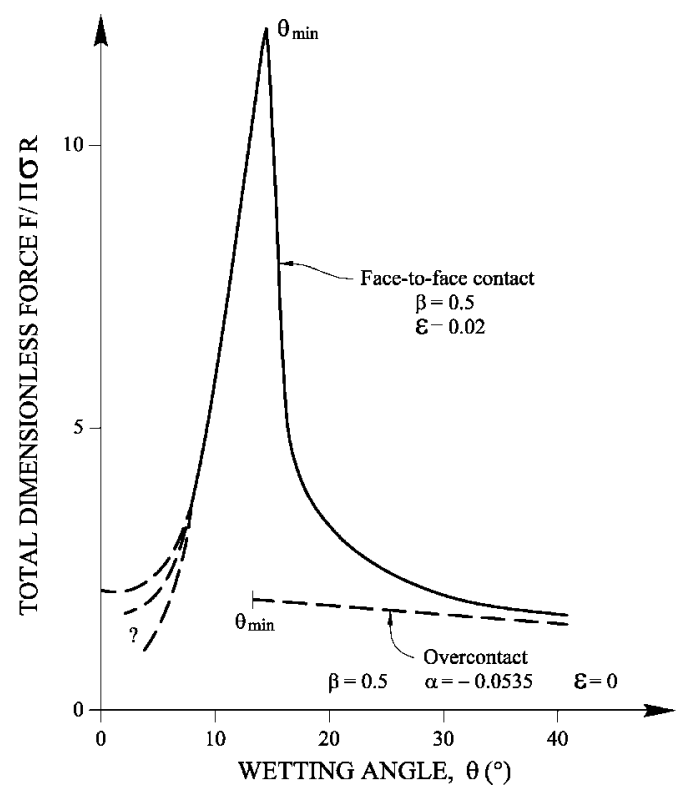

Figure 5. Attraction force in a planar contact.

paper, only point contacts with capillary interaction forces, as defined in Figure 4, will be considered.

Before these forces are integrated into a mechanical framework, a procedure has to be developed in order to obtain the mass of water existing at every meniscus. This mass, in turn, defines the water interaction force. In order to do it, water transfer laws in the porous structure should be addressed. This is presented in the next section.

\section{FLOW AND PHASE CHANGES}

The formulation of water transfer conditions requires first an adequate mathematical representation of the soil geometry. The relative position of the three elements or entities defining the unsaturated porous medium (particles, pores and menisci) is characterized in the model developed by connectivity matrices. Three matrices have been defined: Particle-menisci matrix, pore-menisci matrix and menisci-particle/pore matrix. The first two ones specify the menisci located in the periphery of a given particle or pore. The third connectivity matrix specifies the two particles and pores connected by a given meniscus. Pores are also classified as open to the soil (sample) boundary and inner (or 'closed') pores. The three mentioned matrices are required to establish the microscopic flow equations among the different entities. According to the relaxation scheme used in calculations, it will be assumed that the flow between two elements (pore-pore, pore-meniscus, meniscus-meniscus) at a given time interval is independent of the remaining elements in the soil. Particles are fixed during the time interval in which local flows are defined. 
All the microscopic transfer processes considered (defined below) are described by a simple linear mass-flow rate equation of the type:

$$
\frac{\Delta M_{i j}}{\Delta t}=K_{i j}\left(p_{j}-p_{i}\right)
$$

where $\Delta M_{i j}$ is the mass of a given species interchanged in a time increment $\Delta t$ between entities $i$ and $j . p_{i}$ defines the pressure or concentration of a given species at entity $i$ and $K_{i j}$ is a generalized transfer coefficient which includes geometrical terms and constitutive flow parameters such as permeability or diffusivity. The transfer processes considered have been identified in Figure 6 as a function of the origin and destination of the local flow. Three cases are distinguished:

1. Pore to pore;

2. Pore to menisci; and

3. Menisci to menisci

They affect different species and conduction zones as specified in Table I. Note that the poremenisci interchanges are also properly identified as phase changes.

\section{Flow between pores}

Two flows are distinguished: a convective component, which will be proportional to the gradient of air pressures and a vapour diffusive flow. The convective flow is simulated by means of a

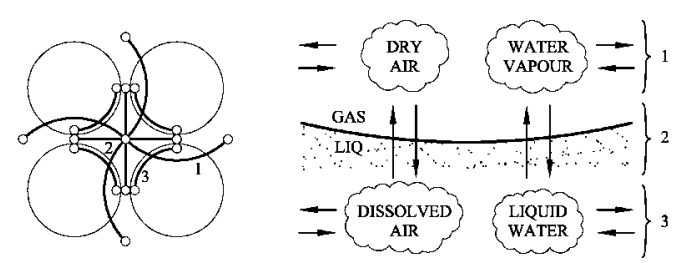

Figure 6. Flow and phase changes considered in the model.

Table I. Definition of flows considered in the model.

\begin{tabular}{|c|c|c|c|}
\hline Species & Origin and destination & Conduction zone & Physical principles \\
\hline $\begin{array}{c}\text { Air-air } \\
\text { Vapour-vapour }\end{array}$ & $\begin{array}{c}1 \\
\text { Pore-pore }\end{array}$ & Conduits between pores & $\begin{array}{l}\text { Pressure gradients } \\
\text { Molecular diffusion }\end{array}$ \\
\hline $\begin{array}{c}\text { Air (gas)-air } \\
\text { (dissolved) }\end{array}$ & 2 & $\begin{array}{c}\text { Interphases gas-liquid in } \\
\text { menisci }\end{array}$ & $\begin{array}{l}\text { Henry's law } \\
\text { (dissolved gas) }\end{array}$ \\
\hline $\begin{array}{l}\text { Water (vapour)-water } \\
\text { (liquid) }\end{array}$ & Pore-meniscus & & $\begin{array}{l}\text { Psychrometric law } \\
(+ \text { a kinetic equation })\end{array}$ \\
\hline Liquid-liquid & 3 & $\begin{array}{l}\text { Liquid films adhered to } \\
\text { particles }\end{array}$ & Pressure gradients \\
\hline Water-dissolved air & Meniscus-meniscus & & Molecular diffusion \\
\hline
\end{tabular}


Poiseuille-type equation. It requires the specification of an equivalent 'hydraulic radius', $R_{\text {eq }}$, and a transfer length, $l_{\text {eq }}$. $R_{\text {eq }}$ can be defined if the cross-sectional area, $A_{\text {eq }}$, of the conduit between neighbouring pores is defined. In the model, this area is given by the areas of the pores located above and below the meniscus connecting the two pores. This transversal area is located in a plane normal to the plane of the model and, as an approximation to its magnitude, it has been assumed to be equal to the average of the free areas of the connected pores:

$$
A_{\text {eq }}=\left(A_{\left(p_{i}\right)}+A_{\left(p_{j}\right)}\right) / 2
$$

where $A_{\left(P_{i}\right)}$ is the area of pore $i$ once the area of the water menisci around it is discounted. This hypothesis assumes a certain regularity of the real 3D structure outside the plane of the simulation model.

Once $A_{\text {eq }}$ is defined, the equivalent radius is simply approximated as:

$$
R_{\mathrm{eq}}=\sqrt{A_{\mathrm{eq}} / \pi}
$$

The equivalent length, $l_{\text {eq }}$, is taken as the distance between the centres of gravity of the two pores considered multiplied by a weighting factor taken as 0.5 in the examples solved.

Once these geometrical quantities are defined, the convective gas flow rates between two pores is given as:

$$
\frac{\Delta V_{\mathrm{eq}, 1 \mathrm{~atm}}}{\Delta t}=\frac{\pi}{8} \frac{\Delta P_{\mathrm{g}}}{l_{\mathrm{eq}}} \frac{R_{\mathrm{eq}}^{4}}{\eta_{\mathrm{g}}}
$$

where $V_{\text {eq, } 1 \mathrm{~atm}}$ is the normalized gas volume (gas volume under $1 \mathrm{~atm}$ of confining pressure). $\eta_{\mathrm{g}}$ is the viscosity of the gas filling the pores.

Similarly, the diffusive flow of water vapour is modelled through a Fick-type equation as:

$$
\frac{\Delta M_{\mathrm{vap}}}{\Delta t}=-D_{\mathrm{vap}} \frac{\Delta C_{\mathrm{vap}}}{l_{\mathrm{eq}}} \pi R_{\mathrm{eq}}^{2}
$$

where $D_{\text {vap }}$ is the diffusion coefficient of vapour in air, $\Delta C_{\text {vap }}$ is the difference in vapour concentrations between the two pores considered and $\pi R_{\mathrm{eq}}^{2}$ and $l_{\mathrm{eq}}$, the cross-sectional area and length available to vapour diffusion.

Flow between pore and meniscus (phase changes)

Water vapour may evaporate or condense from or towards the water menisci if the current vapour pressure in a given pore, $p_{\mathrm{v}}$, is not equal to the equilibrium vapour pressure, $p_{\mathrm{v}}$ eq, at the same pore. The equilibrium vapour pressure is controlled by the water suction, $s$, and the absolute temperature, $T_{\mathrm{a}}$, through the psychrometric equation:

$$
p_{\mathrm{v} \text { eq }}=p_{\mathrm{v}, 0} \mathrm{e}^{-\left(g s / R_{\mathrm{g}} T_{\mathrm{a}}\right)}
$$

where $p_{\mathrm{v}, 0}$ is the equilibrium vapour pressure for free water (which is a known function of temperature), $g$ is the gravity constant, $R_{\mathrm{g}}$, is the gas universal constant and $s$ is the capillary suction given by the Laplace equation (1)

If the pore vapour pressure is not equal to the equilibrium vapour pressure, as given by the psychrometric relationship, the mass rate of vapour exchanged between pore and meniscus is 
given by a kinetic equation:

$$
\frac{\Delta M_{\mathrm{vap}}}{\Delta t}=-K_{\mathrm{vap}}\left(p_{\mathrm{v}}-p_{\mathrm{v}, \mathrm{eq}}\right) A_{\mathrm{LAT}}
$$

where $A_{\mathrm{LAT}}$ is the area of the interphase between the pore and the meniscus considered. In the model, this surface has been taken as to half of the total surface of the toroidal menisci located in the periphery of the pore. This reduction takes into account that a given meniscus is shared between two adjacent pores.

An exponential type of rate equation was proposed by [13] to define the concentration of dissolved air in water, $C_{\text {air }}$ :

$$
\frac{C_{\text {air }}-C_{\text {air }, 0}}{C_{\text {air,eq }}-C_{\text {air }, 0}}=1-\exp \left(-\beta_{\mathrm{M}} \frac{A_{\mathrm{LAT}}}{V_{\mathrm{w}}} \Delta t\right)
$$

where $\beta_{\mathrm{H}}$ is a kinetic constant of phase change, $V_{\mathrm{w}}$ is the volume of water dissolving air and $C_{\text {air,eq }}$ is the concentration at equilibrium as given by Henry's law:

$$
C_{\mathrm{air}, \mathrm{eq}}=1.6 \frac{p_{\mathrm{a}}}{C_{\mathrm{H}}} \rho_{\mathrm{w}}
$$

where $p_{\mathrm{a}}$ is the partial pressure of the dry air in the pores, $C_{\mathrm{H}}$ is Henry's constant and $\rho_{\mathrm{w}}$ the density of water. $C_{\text {air }}, 0$ in Equation (13) is the equilibrium concentration for a reference air pressure.

\section{Flow between menisci}

As indicated in Table I, this flow is assumed to take place along the water films adhered to the soil particles. The first issue to be solved concerns therefore the thickness of these films. Kovacs [14] analysed the water retention properties of soils at high suction and proposed the following equation to relate the film thickness, $\delta$, with the prevailing suction, $s$, and the effective particle diameter, $D_{\mathrm{H}}$ :

$$
\delta=\frac{C_{\mathrm{K}}\left(D_{\mathrm{H}} / \alpha\right)^{1 / 3}}{s^{1 / 6}}
$$

where $D_{\mathrm{H}}, \delta$ and $s$ are given in cm (water), $\alpha$ is a shape coefficient ( $\alpha=6$ for spheres) and $C_{\mathrm{K}}$ is a constant. In order to characterize the 'transport channel' between menisci, a geometry of the film has been defined as illustrated in Figure 7. The geometry of the two menisci considered provides the input data to compute the dimensions of the adhered film (lengths $l_{\mathrm{T}}, l_{C 1}$ and $l_{C 2}$ as defined in Figure 7). The volume of water transferred between two neighbouring menisci connected by means of a water film as illustrated in Figure 7, is modelled through a Poiseuilletype equation:

$$
\frac{\Delta V_{\mathrm{w}}}{\Delta t}=\frac{\gamma_{\mathrm{w}}}{3 \eta_{\mathrm{w}}} I l_{\mathrm{T}} \delta^{3}
$$

where $I$ is the pressure gradient between the two menisci at a distance $l_{\mathrm{C}}$ apart (Figure 7), and $\gamma_{\mathrm{w}}, \eta_{\mathrm{w}}$ are the water unit weight and viscosity, respectively. The transfer of fluid water will carry 


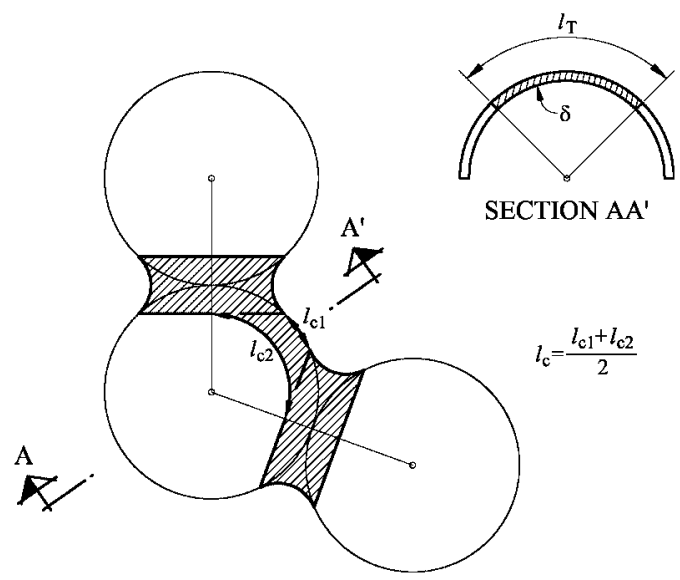

Figure 7. Geometry of the adhered water film between two menisci.

dissolved air. In addition, dissolved air will diffuse according to a Fick-type law:

$$
\frac{\Delta M_{\mathrm{air}}}{\Delta t}=-D_{\mathrm{ad}} \frac{\Delta C_{\mathrm{air}}}{l_{\mathrm{C}}} l_{\mathrm{T}} \delta
$$

which requires the specification of a diffusion coefficient of the air dissolved in water, $D_{\mathrm{ad}}$.

The preceding set of constitutive equations make a number of approximations as reported before. They are not supposed to provide a very accurate description of transfer phenomena at particle scale. The intention was to base the basic water transfer mechanisms on sound physical principles and to include all the relevant ones. In addition, water transfer is not the main purpose of the model, which was developed to understand the particle mechanical interaction mechanisms in the presence of capillary forces. The flow module of the programme has an auxiliary role: it provides the definition of menisci characteristics at every contact and time step when (flow) boundary conditions are defined along time.

Some of the material constants entering the prevailing set of equations are known physical constants (water surface tension, Henry's constant, water and air viscosities, universal gas constant). Others provide the possibility of varying the rate of some transfer processes but they are not fundamental for the specific purposes of the research reported here. It should also be added that, despite the relatively simple character of the transfer equations proposed before, and because they have been defined at a particle or pore scale, they provide as a whole a powerful model to investigate the water transfer mechanisms in granular soils. The set of material constants selected to perform the numerical experiments presented below have been collected in Table II.

The computation of flows has followed an explicit relaxation 'point' scheme. At a given computational time, the flow between two 'entities' (pores or menisci) is considered to be independent of the remaining entities. Some numerical techniques (exponential flow formulation and immediate water mass updating) help to ensure numerical stability and to use relatively large time steps. The most involved part of the analysis is, however, the built-in logic to track the evolution of the pore menisci and particle geometry. In the solved cases presented later, the time increments used in the flow part of the analysis are of the order of $5 \times 10^{-7} \mathrm{~s}$. 

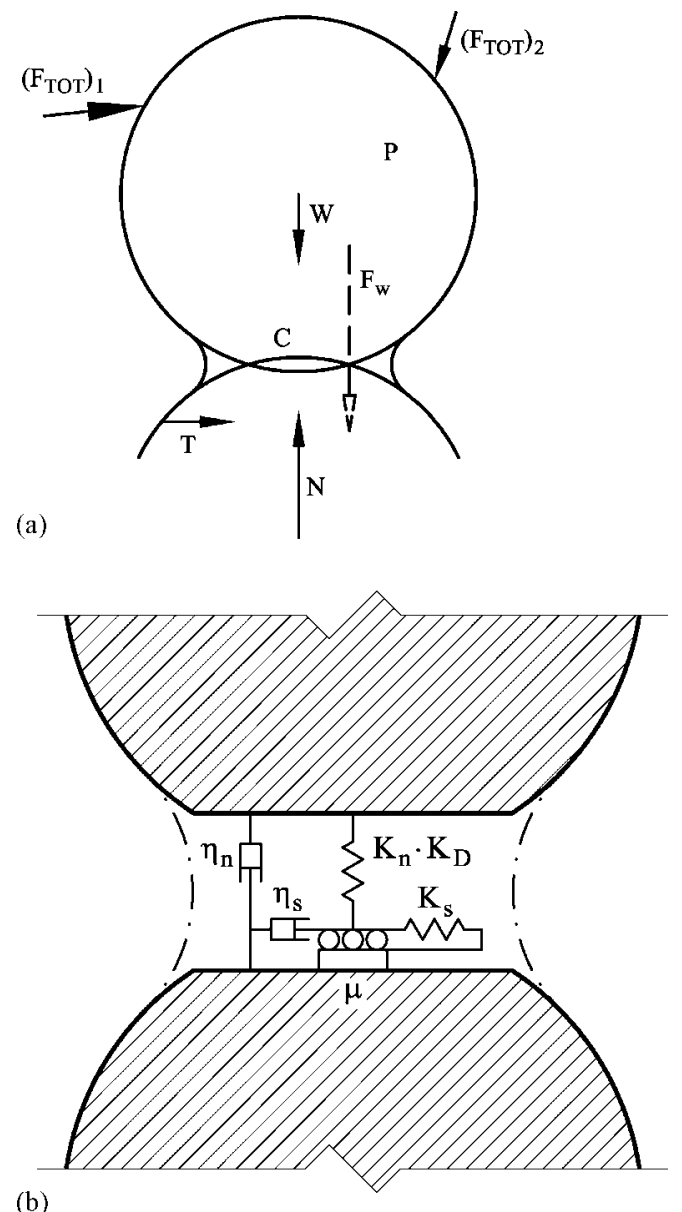

(b)

Figure 8. Particle contact. (a) system of forces (b) rheological constants.

Table II. Material parameters involved in water transfer processes inside the soil structure.

\begin{tabular}{ccc}
\hline Material constant & & Numerical value \\
\hline Water surface tension & $\left(\sigma_{\mathrm{s}}\right)$ & $7.27 \times 10^{-2} \mathrm{~N} / \mathrm{m}$ \\
Henry's constant & $\left(C_{\mathrm{H}}\right)$ & $6.5 \times 10^{-2} \mathrm{kN} / \mathrm{m}^{2}$ \\
Kinetic constant for air solution in water & $\left(\beta_{\mathrm{H}}\right)$ & $8.9 \times 10^{-5} \mathrm{~m} / \mathrm{s}$ \\
Kinetic constant for vapour evaporation & $\left(K_{\mathrm{VAP}}\right)$ & $5.1 \times 10^{-9} \mathrm{~kg} / \mathrm{N} \mathrm{s}$ \\
Water viscosity & $\left(\eta_{\mathrm{w}}\right)$ & $1.005 \times 10^{-3} \mathrm{~kg} / \mathrm{m} \mathrm{s}$ \\
Diffusion coefficient of air dissolved in water & $\left(D_{\mathrm{ad}}\right)$ & $2 \times 10^{-9} \mathrm{~m} / \mathrm{s}$ \\
Air viscosity & $\left(\eta_{\mathrm{a}}\right)$ & $1.8 \times 10^{-5} \mathrm{~kg} / \mathrm{m} \mathrm{s}$ \\
Universal gas constant & $\left(R_{\mathrm{g}}\right)$ & $8.206 \times 10^{-2} \mathrm{at} 1 / \mathrm{K} \mathrm{mol}$ \\
Absolute temperature & $\left(T_{\mathrm{a}}\right)$ & $293.16 \mathrm{~K}$ \\
Equilibrium vapour pressure & $\left(D_{\text {vap }}\right)$ & $239 \times 10^{-5} \mathrm{~m}^{2} / \mathrm{s}$ \\
Diffusion coefficient of vapour in air & $\left(P_{\text {vap, eq }}\right)$ & $2.25 \mathrm{kN} / \mathrm{m}^{2}$ \\
Constant to define the thickness of water films on particles & $\left(C_{\mathrm{k}}\right)$ & $2.5 \times 10^{-3}$ \\
\hline
\end{tabular}




\section{MECHANICAL MODEL}

Mechanical forces acting at a given contact $\mathrm{C}$ (Normal, $N$, and Tangential, $T$, forces) of a particle $\mathrm{P}$ must remain in equilibrium with the remaining forces acting on $\mathrm{P}$ at other contacts $\left(F_{\mathrm{TOT}}\right)_{i}$, mass forces (such as weight, $W$ ) and the 'hydraulic' force, $F_{\mathrm{w}}$, induced by the water meniscus existing in contact $\mathrm{C}$ (Figure $8(\mathrm{a})$ ). $F_{\mathrm{w}}$ is normal to the tangent plane at a given contact. In the case that particle $\mathrm{P}$ has no other contact forces $\left(F_{\mathrm{TOT}}\right)_{i}$ acting on it, given that its weight $W$ is negligible, the normal contact force $N$ will be equal and of opposite sign to $F_{\mathrm{w}}$. In this case, there will be no normal total force acting through the contact.

The shear force $T$, at any contact, has a limiting maximum value given by

$$
T \leqslant \mu N
$$

where $\mu$ is the contact friction coefficient.

In the model developed, the force equilibrium along time and the computation of particle velocities and displacements follows essentially the procedure described by Cundall and Strack $[1,2]$. Contacts (Figure $8(\mathrm{~b})$ ) are characterized by a rheological model in terms of deformation coefficients for normal loads $\left(K_{\mathrm{n}}, K_{\mathrm{D}}\right)$ and shear loads $\left(K_{\mathrm{s}}\right) . K_{\mathrm{n}}$ provides the contact stiffness for virgin loading and $K_{\mathrm{D}}$ for unloading/reloading conditions. The model has therefore the capability of simulating an expansion associated with the relaxation of normal contact forces. Damping coefficients $\left(\eta_{\mathrm{n}}, \eta_{\mathrm{s}}\right)$ in Figure $8(\mathrm{~b})$ are, in general, selected to speed numerical convergence towards equilibrium. Physically, they represent the energy loss due to impact time effects associated with plastification of microasperities and the transient resistance of water menisci to accomodate to a new geometric configuration.

Forces associated with contact deformation (Hertzian contact) and damping, will be represented by $N_{\delta}$ and $N_{\eta}$, respectively (in the case of normal forces) and $T_{\delta}$ and $T_{\eta}$ in the case of shear forces. Figure 9 shows the type of forces acting on a given particle when water menisci exists at the contacts. In addition to the point forces mentioned, additional sources of interaction should be accounted for:

(a) Surface tension at the menisci interphases,

(b) Water pressure in the menisci, and

(c) Water pressure in the pores (gas pressure was omitted in Figure 9)

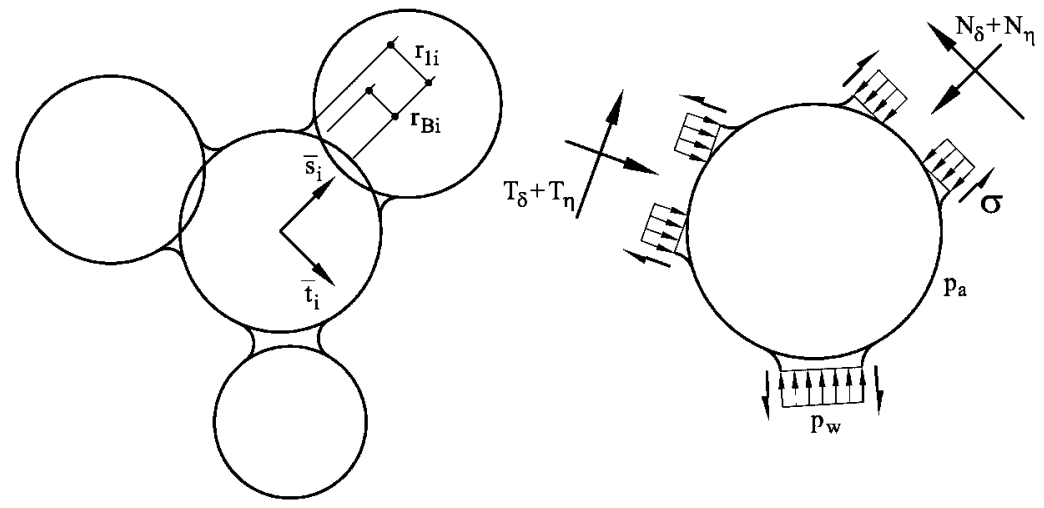

Figure 9. Interaction forces between particles. 
If the gas pressure, $p_{\mathrm{a}}$, is similar in all pores, the normal and tangential forces at each contact are given by (see Figure 9):

$$
\begin{gathered}
\left(N_{\delta}+N_{\eta}+N_{\mathrm{w}}\right)\left(-\bar{s}_{i}\right) \\
\left(T_{\delta}+T_{\eta}\right)\left(-\bar{t}_{i}\right)
\end{gathered}
$$

where the 'hydraulic' force $N_{\mathrm{w}}$ is given by

$$
N_{\mathrm{w}}=\left(p_{\mathrm{w}}-p_{\mathrm{a}}\right)\left(\pi r_{l i}^{2}-\pi r_{\theta i}^{2}\right)-p_{\mathrm{a}} \pi r_{\theta i}^{2}-\sigma 2 \pi r_{l i}
$$

where $\left(\bar{s}_{i}, \bar{t}_{i}\right)$ define a contact orientation and $r_{l i}, r_{\theta i}$ define the size of the meniscus and the extent of the overlapping contact between two particles.

Once the contact forces are computed, the resultant force vector $\left(F_{x}, F_{y}, M\right)$ for every particle may be computed. Simple and double integration of Newton's second law applied to a given particle provides updated velocities and displacements for a simple time step.

A global damping for linear and rotational motions (characterized by damping coefficients $\eta_{\mathrm{GL}}$ and $\eta_{\mathrm{G} \theta}$ ) was also added in the analysis. Numerical stability conditions largely control the selection of mechanical parameters. Nevertheless, the selection of normal and tangential stiffness provide a first approximation to the nature of the solid grains. Two types of grain materials (a stiff one, equivalent to a quartzitic silt and a softer one) were analysed in the experiments reported later. The set of adopted parameters are given in Table III. Time increments for the mechanical part of the analysis were $5 \times 10^{-9} \mathrm{~s}$ for the stiff material and $1.25 \times 10^{-7} \mathrm{~s}$ for the softer one.

The graphical representations of contact forces among particles of the tested sample, presented later, give an indication of the intensity of forces by means of elongated rectangles, as shown in Figure 10. The width of the rectangle is a measure of the intensity of the total contact force. When the hydraulic force, $F_{\mathrm{w}}$, is larger than the mechanical force, $N$, the normal resultant force is considered negative and it is represented by a dotted rectangle.

The inclination of the total force with respect to the normal to the contact tangent plane gives also a measure of the relative intensity of capillary forces. In the limit, a total force directed

Table III. Mechanical parameters used in the analysis.

\begin{tabular}{lcc}
\hline & Stiff particles & Soft particles \\
\hline Stiffness parameters & & \\
$K_{\mathrm{N}}(\mathrm{N} / \mathrm{m})$ & 9800 & 15.68 \\
$K_{\mathrm{D}}(\mathrm{N} / \mathrm{m})$ & 19600 & 31.36 \\
$K_{\mathrm{S}}(\mathrm{N} / \mathrm{m})$ & 2450 & \\
Damping parameters & & \\
$\eta_{\mathrm{N}}(\mathrm{N} / \mathrm{m} / \mathrm{s})$ & $1.96 \times 10^{-3}$ & $7.84 \times 10^{-5}$ \\
$\eta_{\mathrm{S}}(\mathrm{N} / \mathrm{m} / \mathrm{s})$ & $0.98 \times 10^{-3}$ & $3.92 \times 10^{-5}$ \\
$\eta_{\mathrm{GL}}(\mathrm{N} / \mathrm{m} / \mathrm{s})$ & $1.96 \times 10^{-4}$ & $7.84 \times 10^{-6}$ \\
$\eta_{\mathrm{G} \theta}(\mathrm{N} / \mathrm{m} / \mathrm{s})$ & $2.35 \times 10^{-10}$ & \\
Contact friction & & \\
$\quad \mu$ & $0.5\left(=\tan 26.6^{\circ}\right)$ & $0.50 \times 10^{-12}$ \\
\hline
\end{tabular}


i)

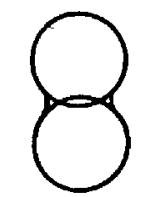

:

ii)
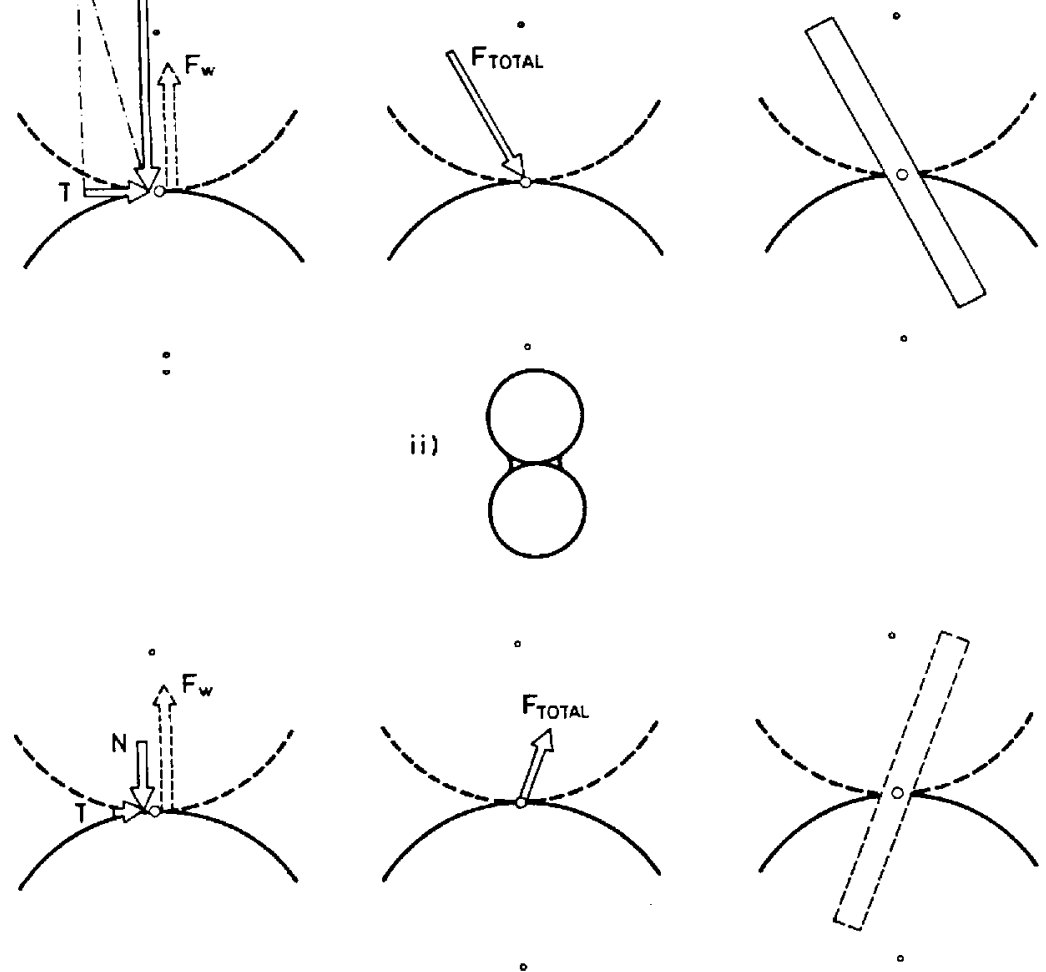

Figure 10. Sign convention and graphical representation of forces at contacts. (i) positive total normal force and (ii) negative total normal force.

parallel to the tangent plane indicates that the contact is in mechanical equilibrium with its own capillary force. It should be recalled that the limiting friction is controlled by the normal mechanical force and not by the total force. It should be noted that the model does not include rate effects in an explicit way. All the stress-strain (or porosity) configurations computed refer to conditions of equilibrium.

The theoretical formulation of the model is now completed. The cases solved refer to the circular 2D configuration described in Figure 2. The extension of the model to a general 3D configuration of particles would require additional developments, especially from a geometrical and programming point of view. However, most of the work reported here would provide the essential background. The interaction between spherical particles would remain unchanged as well as the set of flow and phase change relationships proposed.

An additional comment refers to the simple grain size distribution adopted in the model (three particle sizes: 3,4 and $5 \times 10^{-2} \mathrm{~mm}$ ). This is a model for a fairly uniform silt. This is obviously 
not a limitation of the model itself. This simple arrangement was selected to show the capabilities of the framework and to investigate details of the mechanical response of unsaturated soils. Despite this uniformity in grain sizes, pore sizes extend over a wider range $\left(2.5 \times 10^{-2}-12 \times 10^{-2} \mathrm{~mm}\right.$; see Figure 12). The comparison made in the remaining of the paper with actual test results does not pretend any quantitative agreement. But, when similar trends of behaviour are detected, clues on the basic mechanisms of soil behaviour may be derived from the associated response of the computer model. More complex grain size distributions may be accommodated though and they may eventually lead to a refinement of the results presented here.

\section{SIMPLE TESTS}

The model developed was initially applied to examine the behaviour of an unsaturated granular sample under an isotropic compression followed by a suction reduction. This is a typical stress path, which may lead to a volumetric compression of the soil at constant confining stress (collapse). There was a particular interest in discovering the microstructural mechanisms which lead to collapse.

\section{Isotropic loading at constant suction}

The sample shown in Figure 2 was first equilibrated under a suction $s=90 \mathrm{kPa}$. It was then loaded until a net mean stress $p=10 \mathrm{kPa}$ and finally unloaded, always at a constant suction. Stiffness parameters for the 'rigid' particles were used in this test. Figure 11 shows the evolution of porosity in the loading-unloading cycle. The evolution of pore sizes during loading (Figure 12) shows that the destruction of larger pores explains the overall deformation. Large pores are initially bounded by long chains of particles (six and more), which progressively collapse and give rise to new smaller pores. This process is irreversible as the Figure 11 shows.

Force distributions inside the sample are plotted in Figures 13(a) and 13(b). At the initial state $(p=2 \mathrm{kPa}, s=90 \mathrm{kPa})$ negative normal forces are frequent and therefore hydraulic suction effects dominate. Force chains are clearly visible. Suction effects help to maintain its equilibrium. When the external load reaches the maximum applied value ( $p=90 \mathrm{kPa}$ ) (Figure 13(b)), force chains are enhanced and the relative importance of capillary forces decreases. There are no longer negative normal forces at the contacts.

It is also interesting to examine the local suction changes induced by the application of an instantaneous loading. Figure 14 shows the calculated suctions in the sample menisci as a result of a sudden application of an external confining stress. Particle motions change the geometry of the isolated menisci and local suction is modified. Computed changes in suction amount, in the simulation shown in Figure 16, to a maximum of 40 per cent of the previously existing value. The boundary imposed suction $(s=90 \mathrm{kPa})$ will again prevail in all menisci after a transient adjustment.

\section{Collapse test}

The effect of reducing suction in two steps $(90 \mathrm{kPa} \rightarrow 10 \mathrm{kPa} \rightarrow 0)$ at constant net mean stress $\left(\sigma-p_{\mathrm{a}}\right)=10 \mathrm{kPa}$ is also plotted in Figure 11. The sample reacts by reducing its volume, i.e. it 


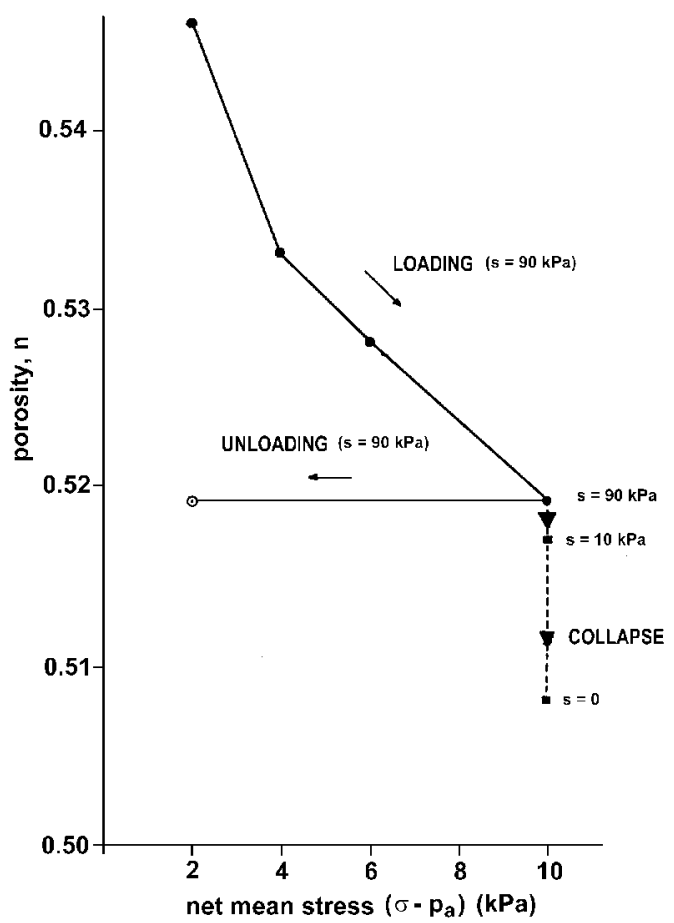

Figure 11. Loading-unloading and collapse behaviour in isotropic test.

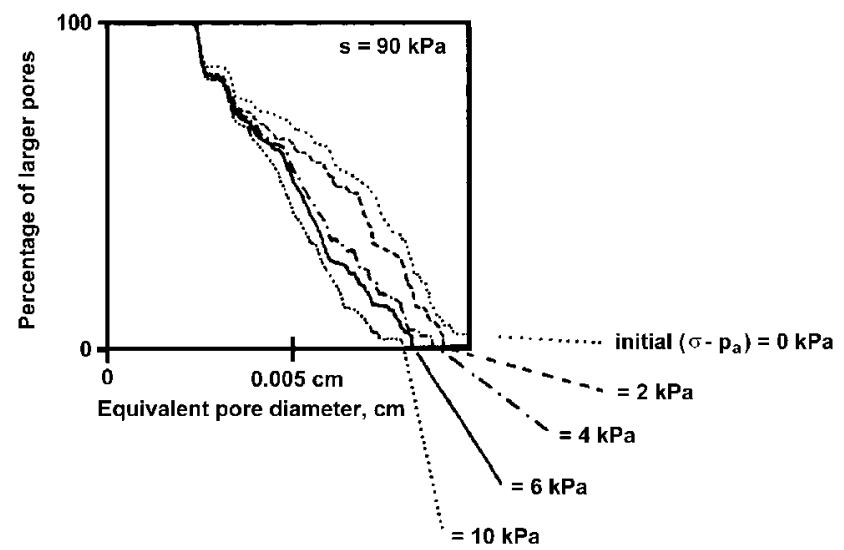

Figure 12. Pore size distributions computed along a loading test.

collapses. Suction reduction is not instantaneous. The change in suction is imposed at the boundary and it progresses inwards due to the liquid transfer laws built into the model. Figure 15 shows how suction evolves towards the centre of the sample. Each dot in this sequence of plots provides the local suction of a meniscus located at a particular radius. 

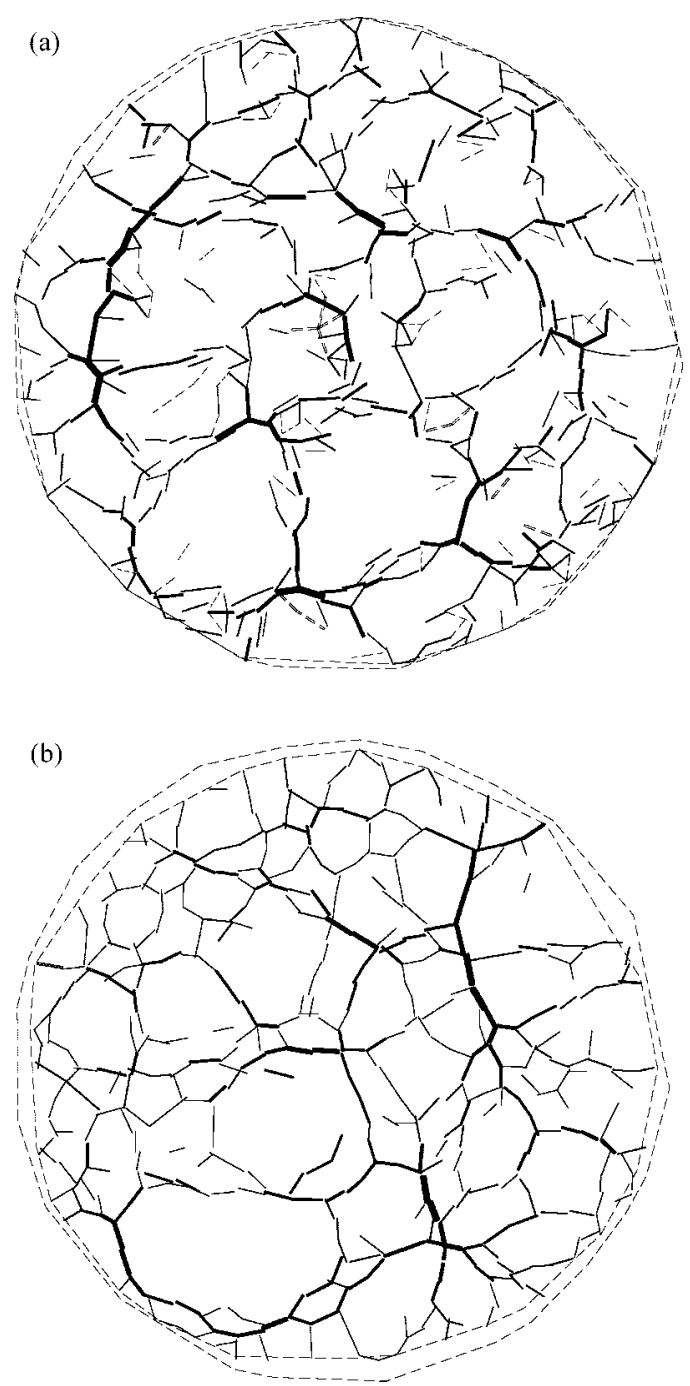

Figure 13. Total forces at the contacts along the loading path at constant suction. Only loads whose intensity is larger than 15 per cent of the maximum are represented. Also shown is the change in specimen shape. (a) $\sigma-p_{\mathrm{a}}=2 \mathrm{kPa}$ and (b) $\sigma-p_{\mathrm{a}}=10 \mathrm{kPa}$.

The new network of force chains, after collapse, is now denser (Figure 16) and this is an indication of new contacts among particles. Porosity reduction is also delayed in time and follows the evolution of suction in the sample. This is shown in Figure 17, which provides the variation of total kinetic energy of particles towards equilibrium. Total kinetic energy increase fast initially and this is an indication of the rearrangement of the structure. Further rearrangements take place at a reduced pace as the wetting progresses. 


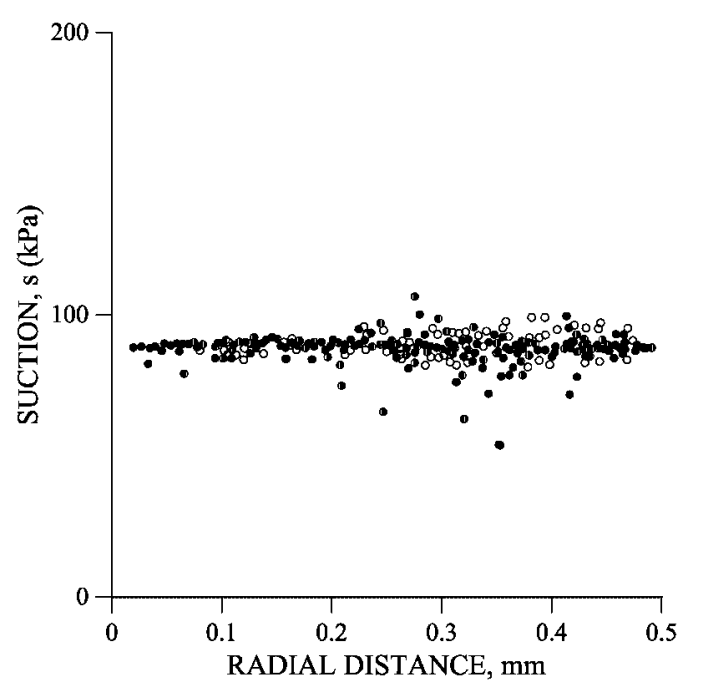

Figure 14. Changes in local suction at menisci as a result of a sudden application of load.
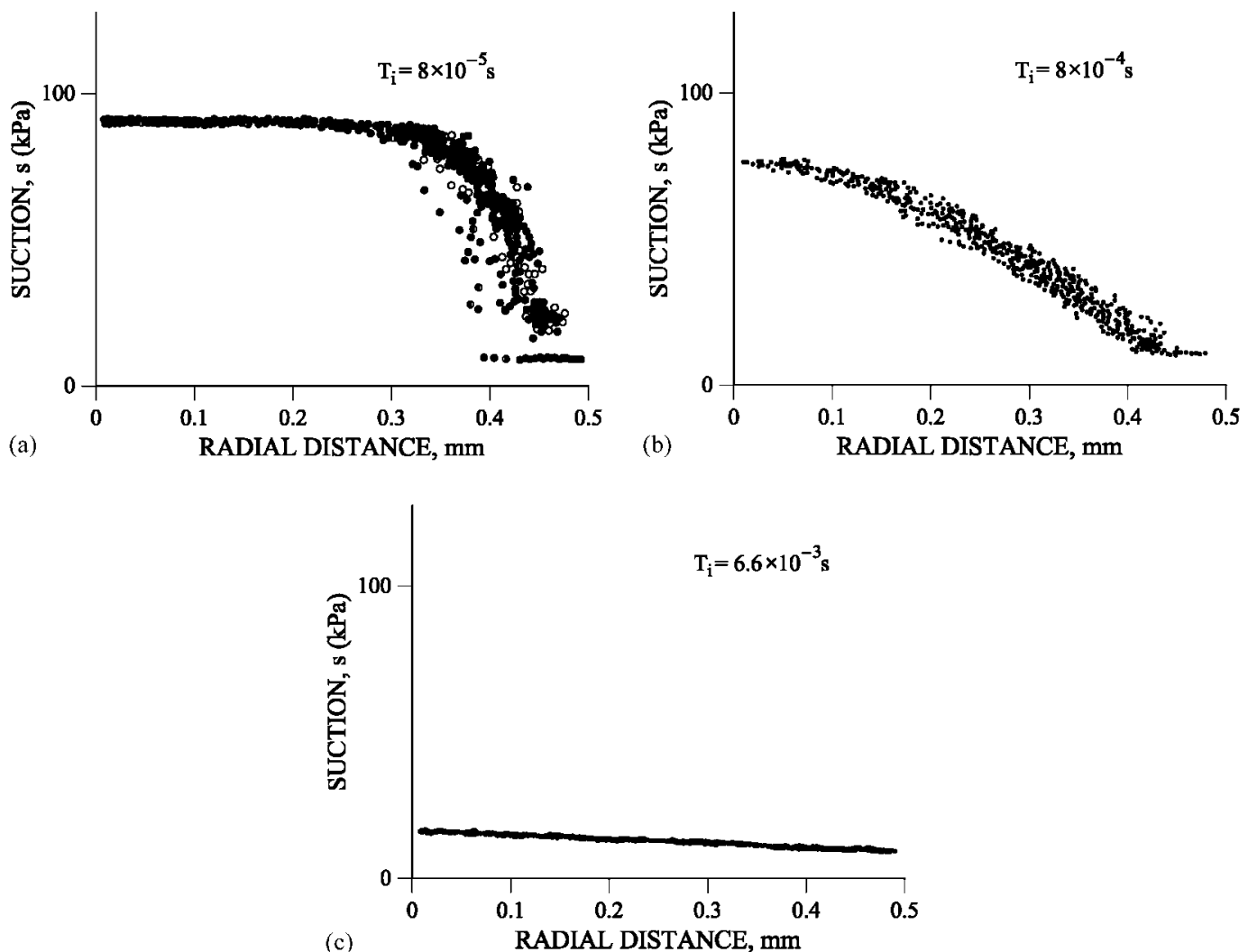

Figure 15. Evolution of suction at menisci when suction is reduced from 90 to $10 \mathrm{kPa} ;\left(\sigma-p_{\mathrm{a}}\right)=10 \mathrm{kPa}$. 


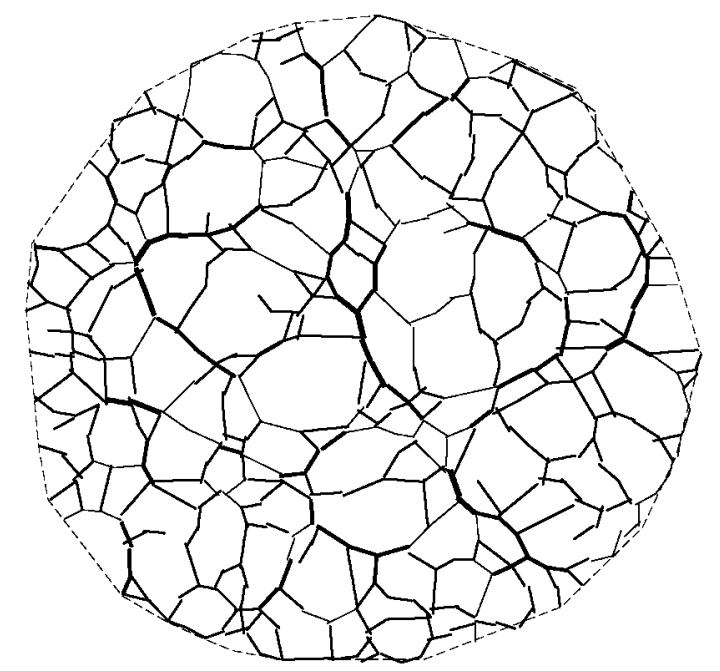

Figure 16. Total force at the contacts when suction is reduced from 90 to $10 \mathrm{kPa}$. Only forces larger than 15 per cent of the maximum are plotted. Maximum force: $6.72 \times 10^{-5} \mathrm{kN}$.

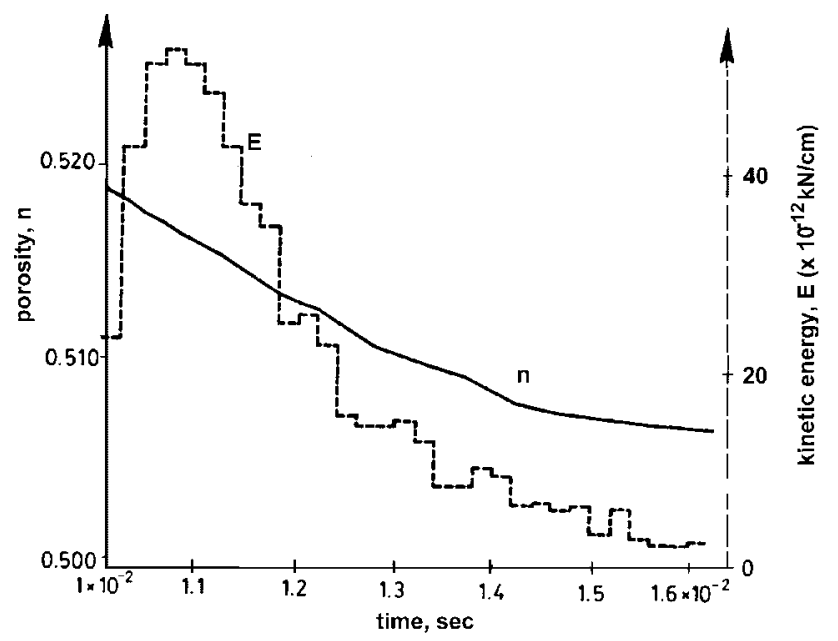

Figure 17. Porosity evolution and variation of total kinetic energy of particles in a collapse process.

\section{STRESS AND SUCTION PATHS IN THE ISOTROPIC PLANE}

Understanding unsaturated soil behaviour under arbitrary paths in the isotropic plane: mean stress vs suction, is one of the key aspects for the development of constitutive models. In the isotropic plane, simple tests such as loading under constant suction or suction reduction at constant net mean stress plot as straight lines parallel to the two axis. However, these common 
tests say nothing on the reversibility of deformations or on the amount of dependence of deformations on alternative paths connecting two given stress-suction states.

State surfaces [15-17] are simplified models to describe volumetric changes of unsaturated soils. They imply reversibility of deformations and therefore may be classified as (linear or nonlinear) elastic models. Elastoplastic models, which adopt a 'Loading-Collapse' (LC) yield locus in the isotropic plane to describe macrostructural soil rearrangements [18-21] predict stress path independence of computed deformations in loading-wetting paths. However, they predict a stress path dependence in loading sequences which involve drying processes. Available information from laboratory tests is not, however, fully conclusive on this issue. For instance, the elastoplastic models mentioned predict that after full wetting at constant mean stress, the resulting void ratio plots on the saturated compression line. Tests on a loess soil reproduced in Figure 18 indicate that the porosity after flooding may not reach the saturated compression line. A microstructural model may provide additional data on these questions, which may eventually lead to the development of more firmly based constitutive models.

Three types of paths have been investigated: loading-wetting sequences; loading-drying sequences and the application of suction cycles at constant net mean stress. In these tests, the softer contact stiffness parameters were used.

\section{Loading-wetting sequences}

Two samples are first equilibrated at a common initial point (point A in Figure 19: $p=2 \mathrm{kPa}$; $s=90 \mathrm{kPa}$ ). Two alternative stress paths are then applied to the sample in order to reach the final saturated state at a common net mean stress (Point F in Figure 19: $p=4 \mathrm{kPa} ;=0$ ): ACD and AEF.

Path AC is a one-step flooding of the sample. The change in porosity along this path is shown in Figure 19(b). It is interesting to see how the sample experiences first a small overall expansion associated with the elastic relaxation of Hertzian contacts among particles. This stage was not observed in the test shown in Figure 11 where the confining load was higher $(p=10 \mathrm{kPa})$ and the particle contacts stiffer. Beyond the initial increase in volume the sample collapses. In fact, this is the type of response predicted by the elastoplastic models when the wetting path crosses first the elastic domain before hitting the LC yield surface [19].

In engineering terms, collapse is associated with the effect of suction reduction at constant confining stress. A different collapse mechanism would correspond to the reduction of the grainto-grain friction. Even if suction is maintained constant, a lubrication of contacts would lead to

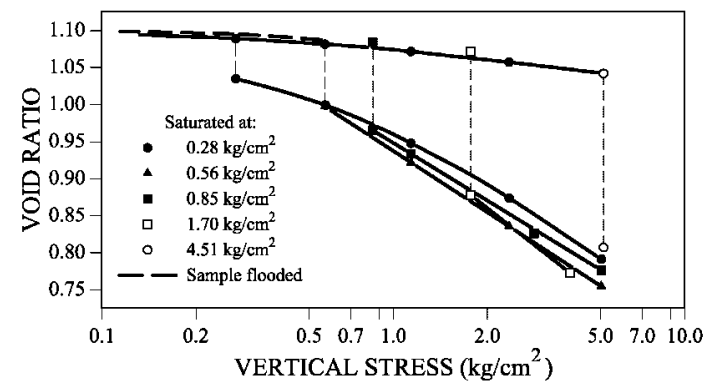

Figure 18. Collapse tests on loess for different confining stresses [25]. 

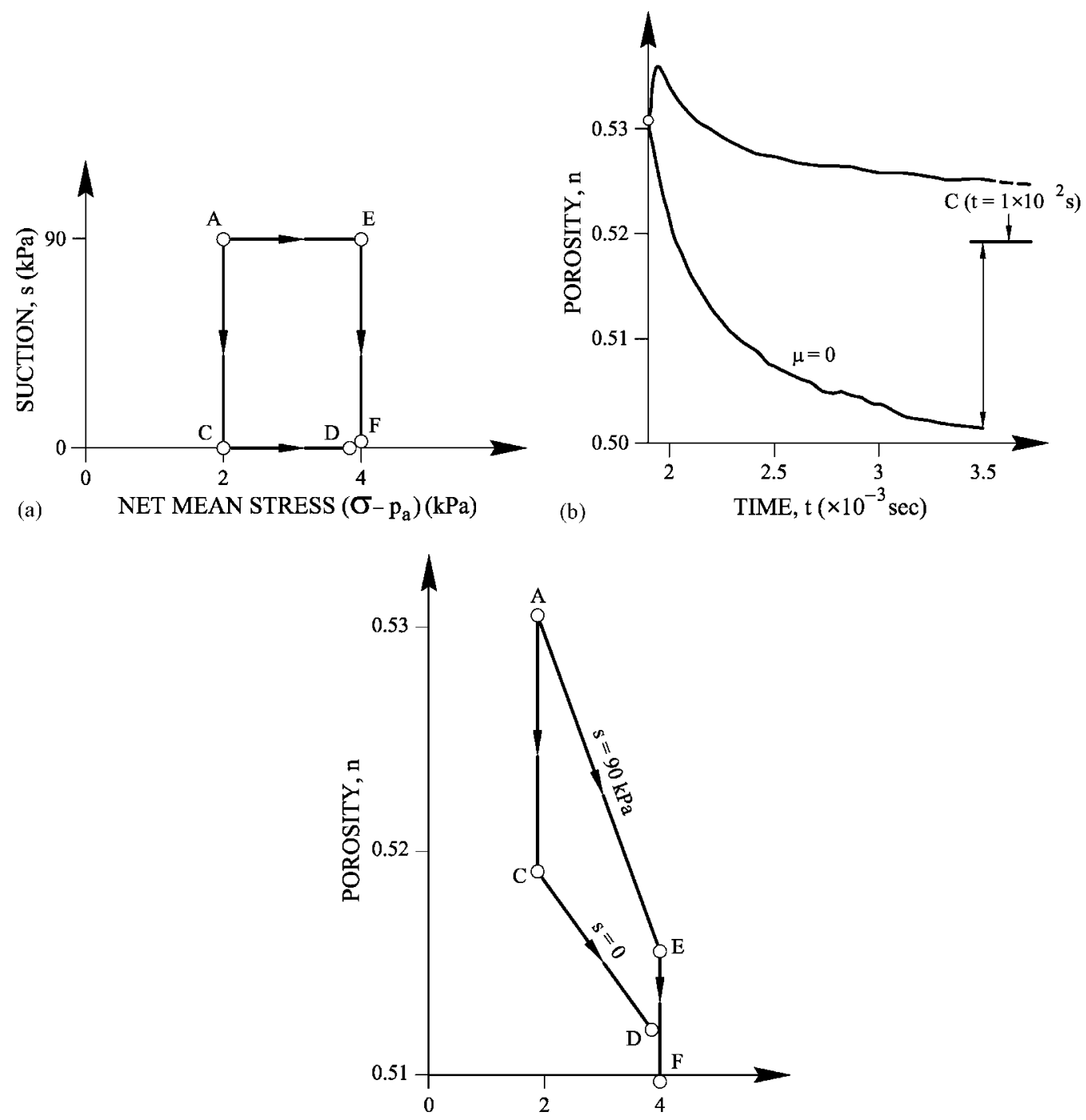

(c) NET MEAN STRESS $\left(\sigma_{-} p_{a}\right)(\mathrm{kPa})$

Figure 19. Isotropic loading-wetting tests: (a) stress paths; (b) porosity evolution in path AC. Also indicated is the collapse induced when friction is reduced to zero $(\mu=0)$ at constant suction; (c) porosity variations.

a rearrangement of the current soil structure and presumably to a reduction in volume. This phenomenon is unlikely in common engineering applications but may be easily investigated with the help of the microstructural model. Figure 19(b) shows (curve $\mu=0$ ) the effect of reducing to zero the friction among particles (while suction is maintained at its initial value $s=90 \mathrm{kPa}$ ). A strong collapse takes place. It may be viewed as the maximum collapse potential of a given soil structure. It becomes clear that the nature of collapse on wetting is associated with the modification of internal stresses due to capillary force reduction and not to lubricating effects among grains. 
The results of the two tests, ACD and AEF, have been plotted in terms of overall porosity variations in Figure 19(c). It may be seen that the computed collapses decrease with the intensity of confining stress (compare segments AC and EF in Figure 19(c)). This result may surprise in view of reported experimental data, especially for compacted soils [18]. But it should be realized that the initial state A corresponds to an open soil structure. The first loading, at constant suction, modifies the initial structure which becomes denser and therefore, with a reduced collapse potential. This behaviour is also observed in the laboratory when low density sandy soils are tested. This is the case reproduced in Figure 20. It reports the results of oedometer tests carried out in samples of residual granitic soils from S. Feliu de Guixols, in the North East Spanish coast (Costa Brava). A collapse of this soil was at the origin of widespread cracking of several family houses. Two samples of the sandy soil, with a low water content $(w=6$ per cent) far from saturation, were loaded under two vertical stresses: 40 and $160 \mathrm{kPa}$, respectively. Once equilibrated the samples were soaked.

Figure 20(a) shows the deformations measured along time and Figure 20(b), the approximate suction-stress paths imposed on the samples (the initial suction was not measured but it was presumably very high).

The rate of change of porosity of these oedometer tests is small if compared with the fast model changes, as implied in Figure 19(b). This is an expected result since the size of the oedometer specimen $(20 \mathrm{~mm}$ in thickness and $70 \mathrm{~mm}$ in diameter $)$ is much larger than the 'small' computer sample ( $1 \mathrm{~mm}$ in diameter). In addition, the natural sandy soil had a significant amount of fine particles (silt, clay). Water transfer rates upon wetting are, therefore, not
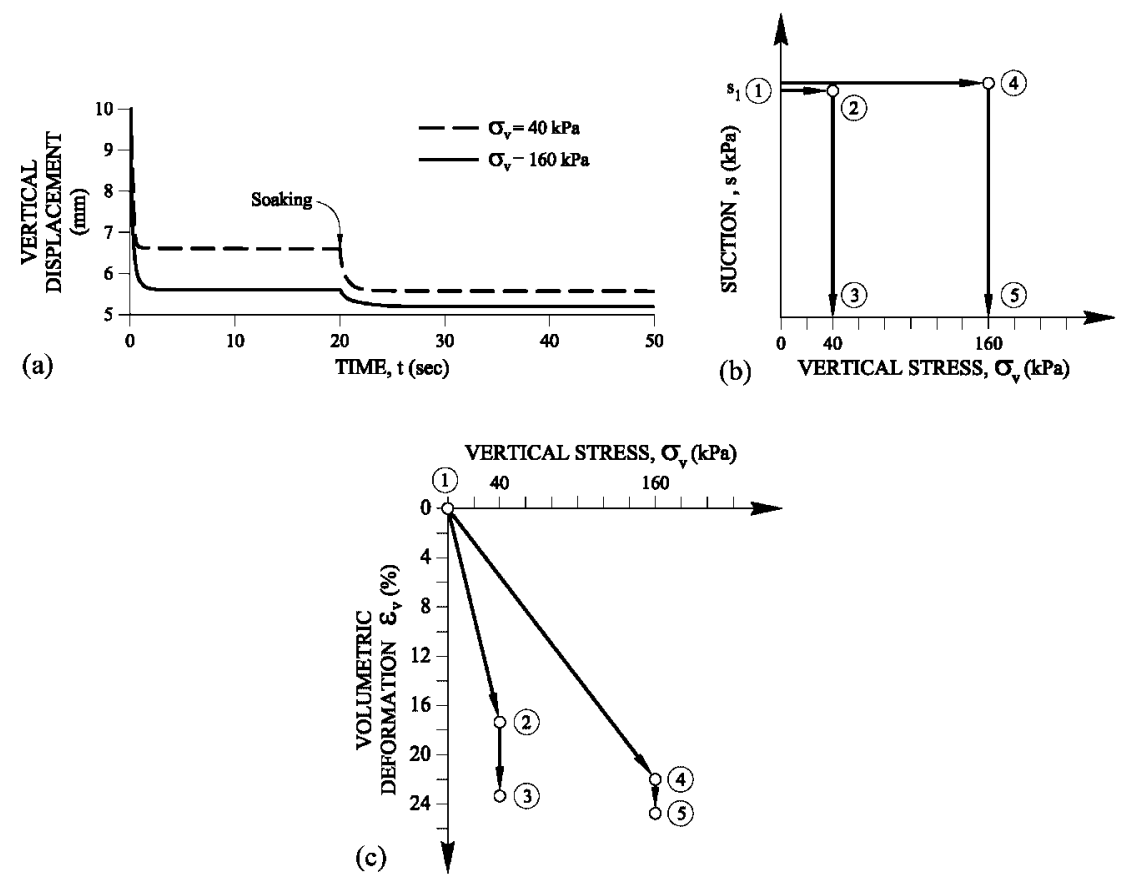

Figure 20. Oedometer tests on a residual granitic sand. (a) Deformations measured in two tests, (b) stress paths and (c) volumetric deformations. 


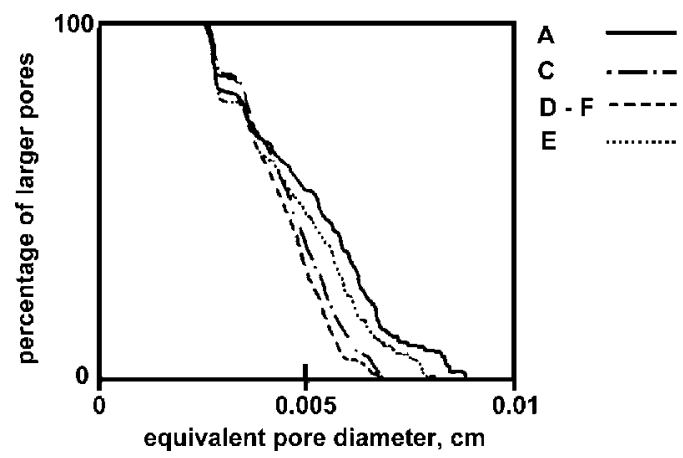

Figure 21. Pore size distributions at different stress-suction states as defined in Figure 19(a).

comparable. Finally the apparatus compliance will tend also to retard in time the response of the soil specimen.

The stress-deformation curves are shown in Figure 20(c). The loading at constant water content compressed significantly both samples. On subsequent wetting, the denser sample (compressed under $160 \mathrm{kPa}$ ) did not collapse as much as the other, which had a lower density after the load compression. This explanation may be given, in parallel terms, to the results of the numerical test performed.

Additionally, the final state (D and F in Figure 19(c)) is not the same unlike the prediction of simple elastoplastic models based on single 'LC' yield curves. It may be concluded that the deformations associated with the loading stage, previous to the suction reduction have induced significant variations of the initial soil structure. A comparison of the pore size distributions at different stress-suction states of these two numerical tests (Figure 21) shows again that macroscopic deformations are associated with the destruction of the largest voids. The final porosity at $\mathrm{D}$ and $\mathrm{F}$, although different from each other is, however, very similar.

\section{LOADING-DRYING SEQUENCES}

Figure 22(a) indicates the paths of the tests carried out. The initial state, C, corresponds to a grain configuration which has already experienced a collapse from an initial suction $s=90 \mathrm{kPa}$. This explains that its initial porosity is somewhat smaller than the initial porosity of the previous tests. The computed porosity variations are given in Figure 22(b).

Along the drying paths (segments $\mathrm{CH}$ and $\mathrm{DG}$ ) the contacts among spheres will compress as menisci develop and impose a force attraction. The macroscopic effect is a sample compression, most of it elastic, although irreversible (plastic) components of deformation are also present as the application of suction cycles reveal (see next series of tests). Again in this case the final porosities of both tests (points I and G) are not equal as the simple elastoplastic models mentioned before predict.

Wetting-drying cycles

Several suction cycles were imposed at a constant net mean stress $p=2 \mathrm{kPa}$ (Figure 23(a)). The evolution of porosity as suction changes in the range $0-90 \mathrm{kPa}$ is given in Figure 23(b). The first 

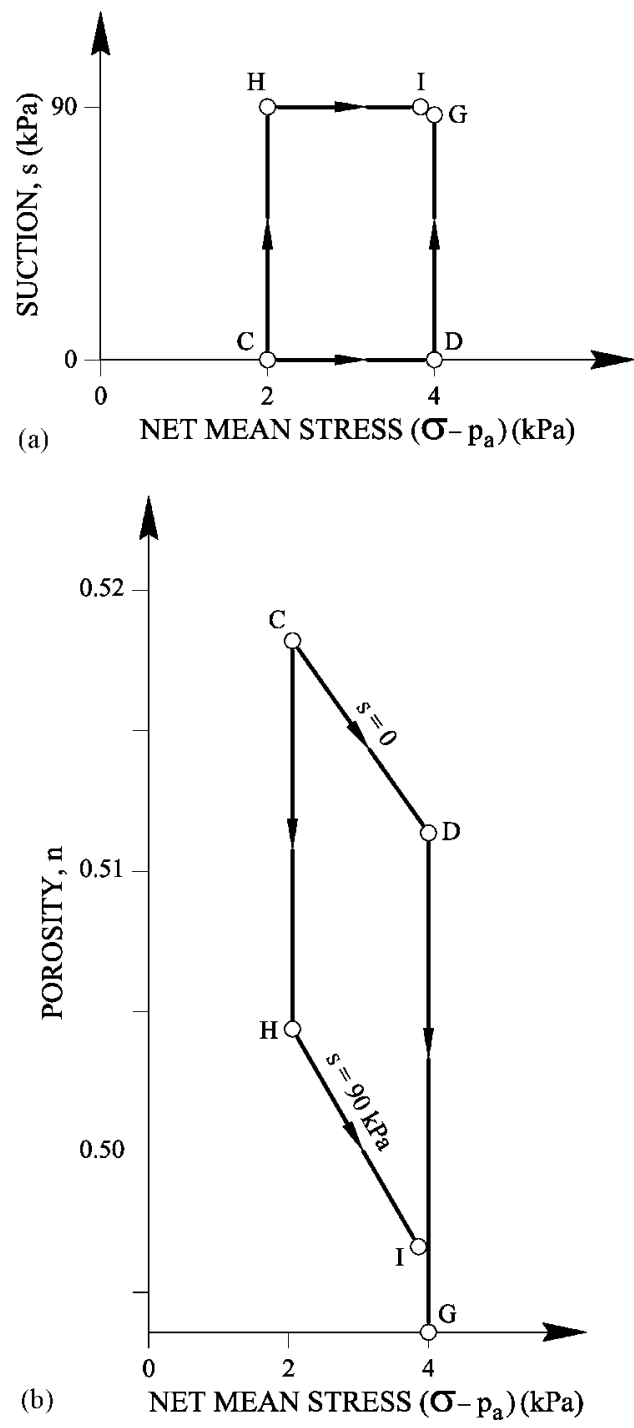

Figure 22. Isotropic loading-drying tests: (a) Stress paths in two loading-drying tests, (b) porosity variations along paths shown in (a).

wetting induces a collapse and the subsequent drying leads to an additional sample compression. The second wetting does not cause any further collapse. Instead a definite expansion is recorded due to the capillary stress relaxation at the particle contacts. These results are so far in good qualitative agreement with the predictions of a single ' $L C$ ' type of elastoplastic model as Figure 24 points out. The initial stress state (Point A in Figure 24(a)) lies on a yield curve ( $\left.\mathrm{LC}_{1}\right)$. The first wetting (path AC) displaces the LC yield locus to a second and final position $\left(\mathrm{LC}_{2}\right)$. During this wetting, a plastic compression is added to an elastic expansion due to suction 

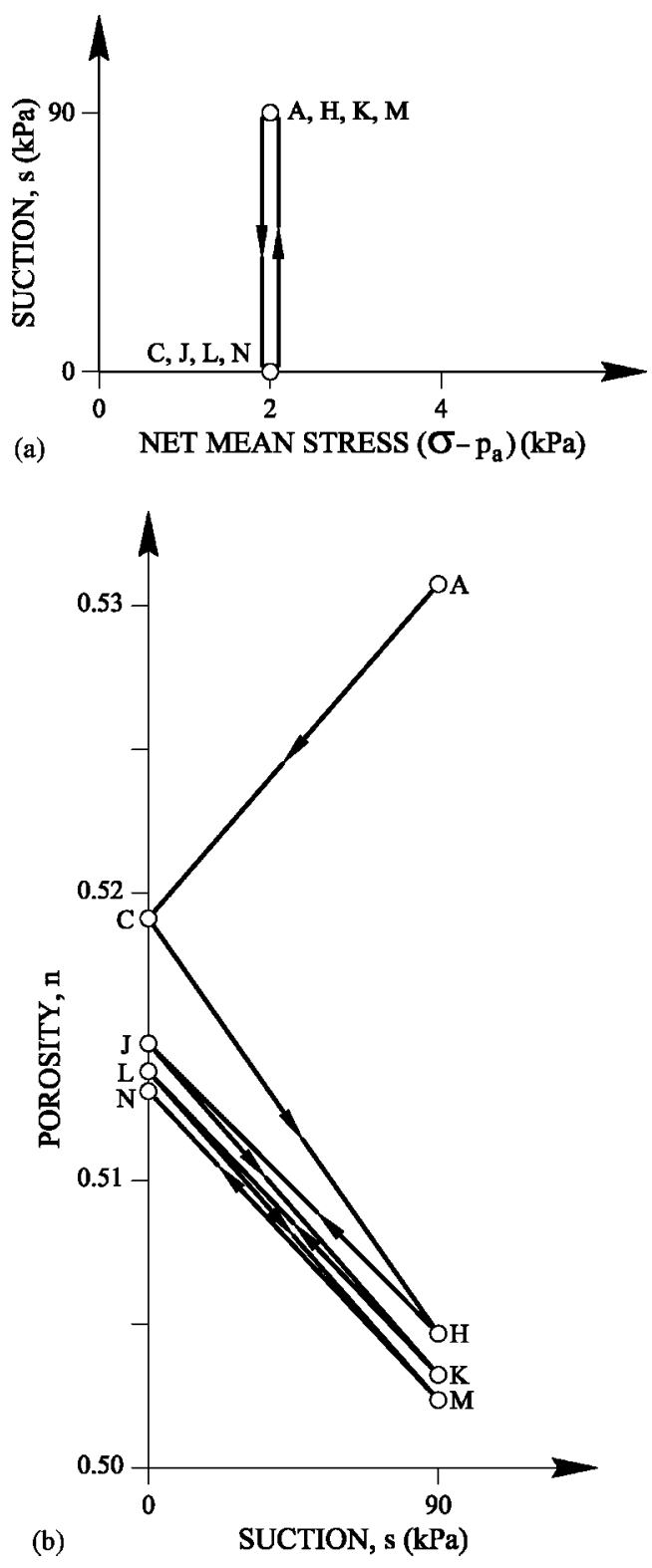

Figure 23. Suction cyles. (a) Stress paths. Sequence: A, C, H, K, L, M, N, (b) Porosity variations.

reduction. The net effect is a reduction of sample volume (collapse). The elastic domain has now increased in size and subsequent drying-wetting cycles remain reversible as indicated in Figure 24(b). The microstructural model behaves in a somewhat different manner. Although it is apparent that after the first wetting, the sample has entered into a 'quasi-elastic' behaviour, the accumulation of cycles leads to a progressive compression of the sample. However, the 

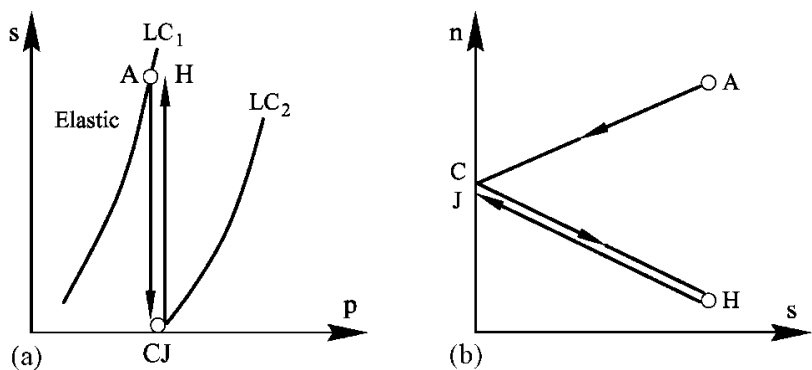

(b)

Figure 24. Qualitative predictions of an LC elastoplastic model against wetting-drying cycles. (a) Stress paths and yield curves in the $(p, s)$ plane. (b) Porosity changes for wetting-drying cycles.

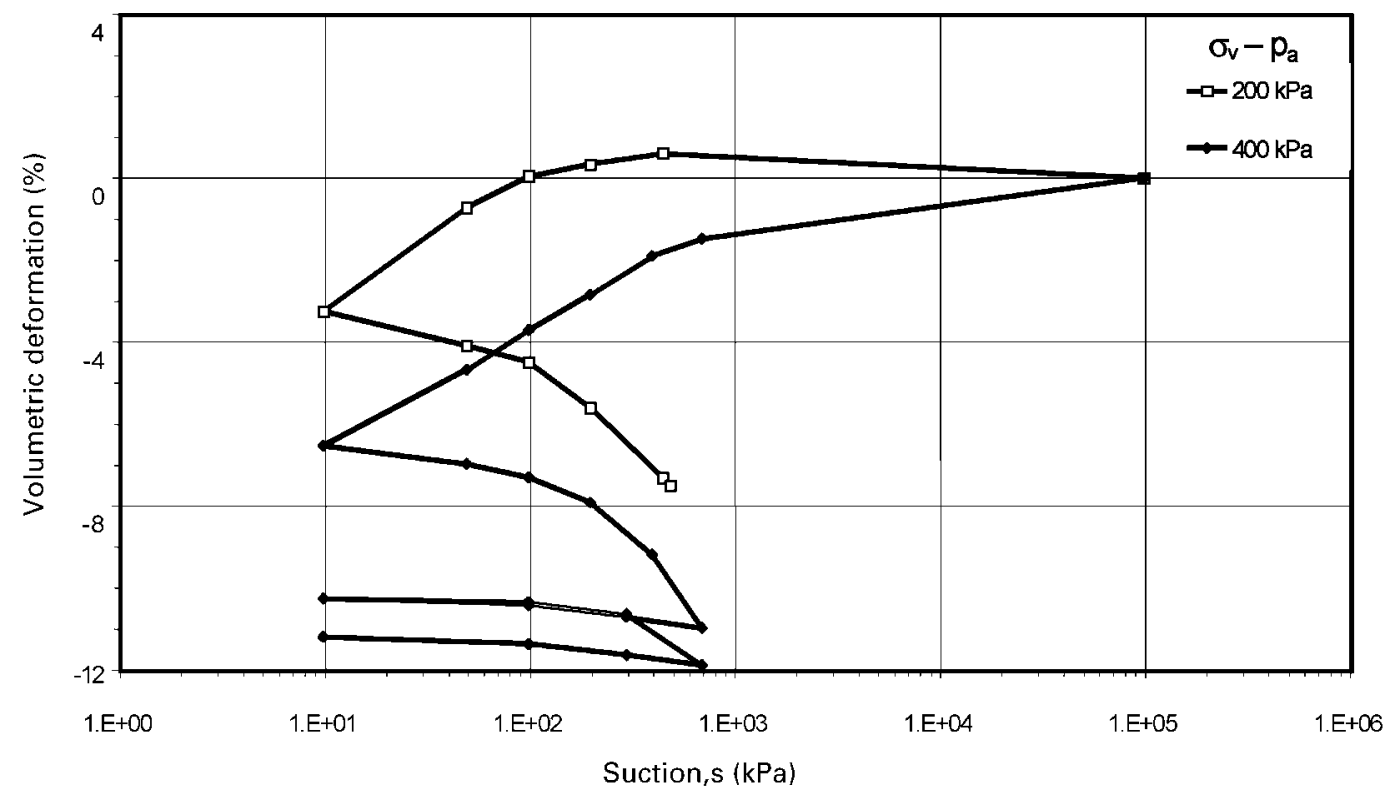

Figure 25. Results of suction controlled oedometer tests on samples of compacted Boom clay pellets for $\sigma_{\mathrm{v}}-p_{\mathrm{a}}=200$ and $400 \mathrm{kPa}[22]$.

irreversible component of the deformation reduces as the numbers of cycles increases and eventually the sample seems to reach a purely elastic behaviour.

This type of behaviour has also been observed in the laboratory. Figure 25 shows the results of applying suction cycles to a sample with a marked granular structure: particles were pellets $2 \mathrm{~mm}$ in average dimension of highly compacted clay $\left(\gamma_{\mathrm{d}}=20 \mathrm{kN} / \mathrm{m}^{3}\right)$ [22]. However, the initial dry density of the sample was only $13.7 \mathrm{kN} / \mathrm{m}^{3}$. Suction cycles were applied in a suctioncontrolled oedometer cell under different normal stresses. The results plotted in Figure 25 correspond to vertical stresses $\sigma_{\mathrm{v}}=200$ and $400 \mathrm{kPa}$. These confining loads are capable of inducing a significant collapse on first wetting. The subsequent application of suction cycles 
leads to a volumetric response of the sample which is qualitatively similar to the numerical test on a purely granular material of open structure.

\section{THE INFLUENCE OF DEVIATORIC STRESSES ON COLLAPSE (SOFT PARTICLES)}

The effect of deviatoric stress states on collapse deformations upon wetting may be experimentally investigated in a triaxial cell. Tests of this kind on samples of compacted clayey sand have been reported in Reference [23]. The specimens were first equilibrated under a given deviatoric stress state characterized by a ratio of axial and radial stresses $\left(\sigma_{\mathrm{a}} / \sigma_{\mathrm{r}}\right)$ and then wetted at constant $\left(\sigma_{\mathrm{a}} / \sigma_{\mathrm{r}}\right)$. Axial and radial stresses were recorded during the wetting process. Their tests showed that:

- Volumetric collapse was controlled by the mean total stress and not by the deviatoric stress.

- Axial and radial collapse strains increased with increasing deviatoric stress ratio.

These tests were interpreted in Reference [24] within the framework of an elastoplastic constitutive model. Figures 26 and 27 reproduce some experimental results which justify the preceding conclusions. Also indicated in these figures, taken from Reference [24], is a comparison between experimental observations and model predictions. Similar tests have been performed numerically following the stress paths shown in Figure 28(a). All the tests start in point $\mathrm{A}$, once the granular structure is equilibrated under an isotropic stress state $(p=2 \mathrm{kPa}$, $s=90 \mathrm{kPa})$. Then, deviatoric stresses of increasing intensity are applied until states LA, LB and LC are reached. Deviatoric stresses are characterized through a mobilized friction angle, $\phi_{\text {mov }}$, defined as

$$
\sin \phi_{\mathrm{mov}}=\frac{\left(\sigma_{1}-p_{\mathrm{a}}\right)-\left(\sigma_{2}-p_{\mathrm{a}}\right)}{\left(\sigma_{1}-p_{\mathrm{a}}\right)+\left(\sigma_{2}-p_{\mathrm{a}}\right)}=\frac{\sigma_{1}-\sigma_{2}}{\sigma_{1}+\sigma_{2}}=\frac{\left(\sigma_{1} / \sigma_{2}\right)-1}{\left(\sigma_{1} / \sigma_{2}\right)+1}
$$

A given mobilized friction angle, defines therefore a stress ratio. Once deformations are stabilized at LA, LB and LC, suction is reduced to the final saturation states LAC, LBC and LCC.

The deformations calculated along these three stress-suction paths have been plotted in Figure 28(b). The plot gives the change experienced by the vertical and horizontal dimensions of

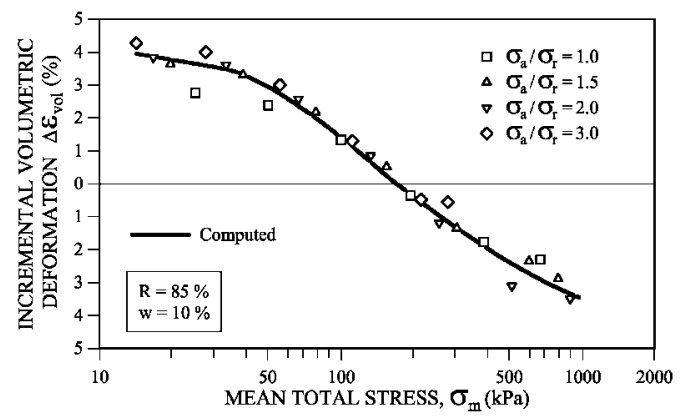

Figure 26. Variation of volumetric deformations as a function of total mean stress and stress ratio, measured in triaxial wetting tests [23,24]. 

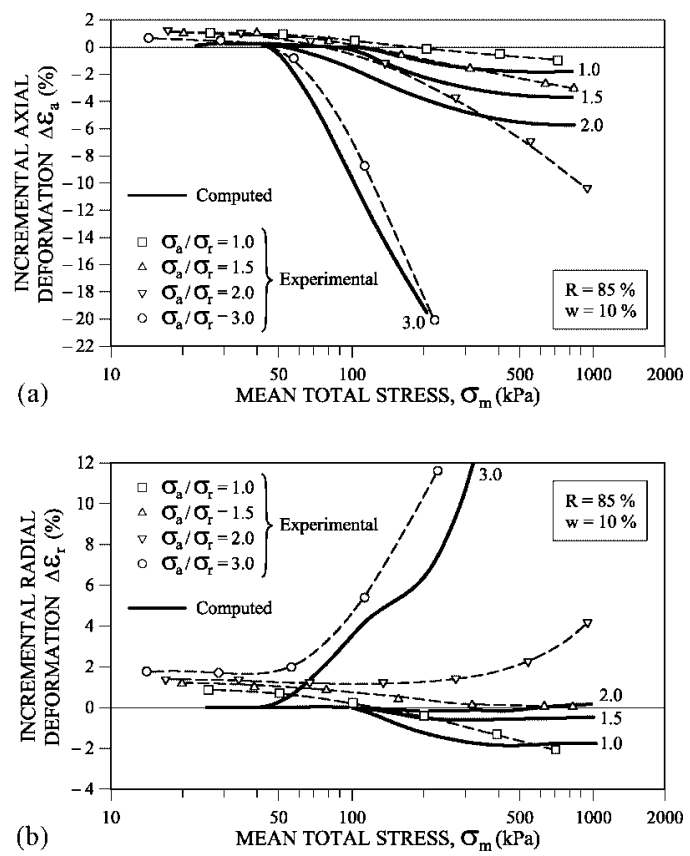

Figure 27. Variation of axial and radial collapse deformations with total mean stress and stress ratio, measured in triaxial wetting tests $[23,24]$.

the specimen $\left(l_{11}\right.$ and $\left.l_{22}\right)$ along the computational time. The initial diameter of the specimen was $l_{11}=l_{22}=9.3 \times 10^{-2} \mathrm{~cm}$. The figure shows the small changes in sample dimensions when the deviatoric stresses are applied at constant suction (points LA, LB and LC). Wetting leads, in the three cases, to a significant change in sample dimensions. Under the maximum deviatoric stress imposed $\left(\phi_{\mathrm{mov}}=30^{\circ}\right)$ the circular arrangement of particles was still far from equilibrium conditions when the analysis was stopped because of the large specimen distortion. It is seen that collapse deformations in vertical and horizontal directions are similar and of opposite sign and they increase with the intensity of deviatoric stress. Computed deformations are plotted in Figure 29, for a common computational time $\left(t=7 \times 10^{-3} \mathrm{~s}\right)$ as a function of the mobilized friction angle.

It seems, therefore, that volumetric deformations upon wetting are not essentially affected by deviatoric stress states and this is further checked in Figure 30, where changes in porosity for all the tests performed (including the isotropic collapse test AC) are plotted against suction. Porosity changes are similar, regardless of the deviatoric stress applied.

The qualitative agreement between the numerical results and the experimental behaviour reported in Reference [23] is significant. This result points out that capillary interaction phenomena among particles and the nature of a granular medium are capable of explaining relevant features of unsaturated soil behaviour, even if the soil has a non-negligible clay component as it was the case for the clayey sand tested and reported in Reference [23].

Computed deformations (Figure 28(b)) for $\phi_{\text {mov }}=30^{\circ}$ indicate that the sample has failed under saturated conditions. Large deformations were also recorded for $\phi=20^{\circ}$ once the specimen was flooded. However, if the suction $s=90 \mathrm{kPa}$ is maintained an equilibrium state 

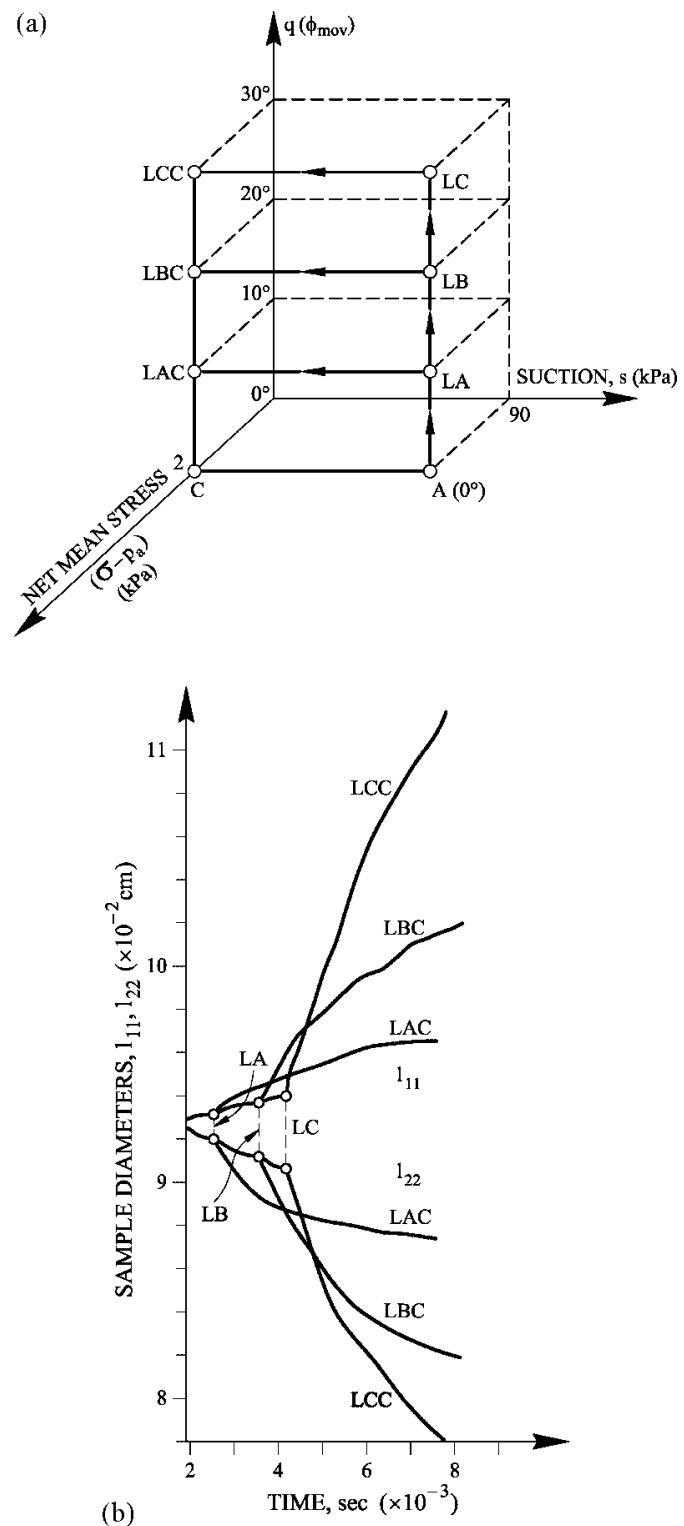

Figure 28. Deviatoric tests. (a) Stress paths, (b) Change in sample dimensions along time.

could be found for $\phi_{\mathrm{mov}}=30^{\circ}$. Internal capillary forces explain that this strength increase is to be associated with suction. In order to gain insight into the nature of the capillary action, contact forces have been plotted in Figure 31 for the stress state LC $\left(\phi_{\text {mov }}=30^{\circ}, s=90 \mathrm{kPa}\right.$, see Figure 28(a)). On the right-hand side of the figure, all forces are represented using the graphical plotting criteria described previously. On the left-hand side of the figure, only negative normal forces are plotted. These are cases in which the capillary force is larger than the mechanical 


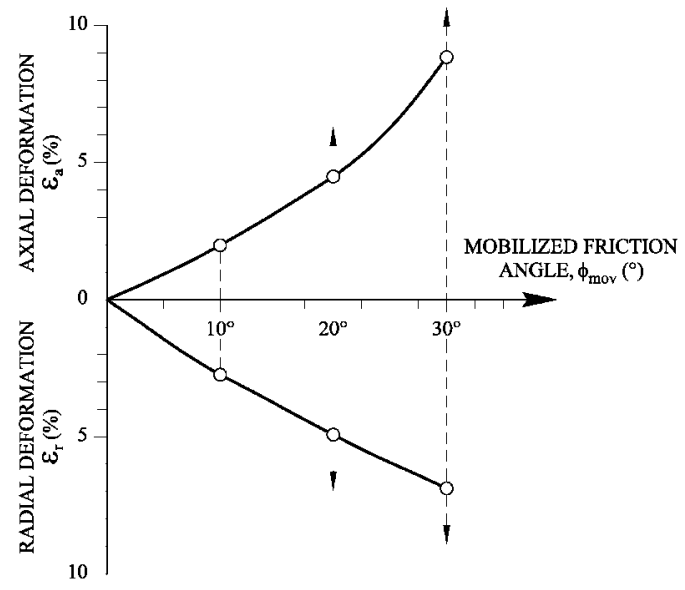

Figure 29. Variation of axial and radial deformations as a function of mobilized friction angle in wetting tests. Arrows indicate the trend of the deformation rate when the simulation was interrupted.

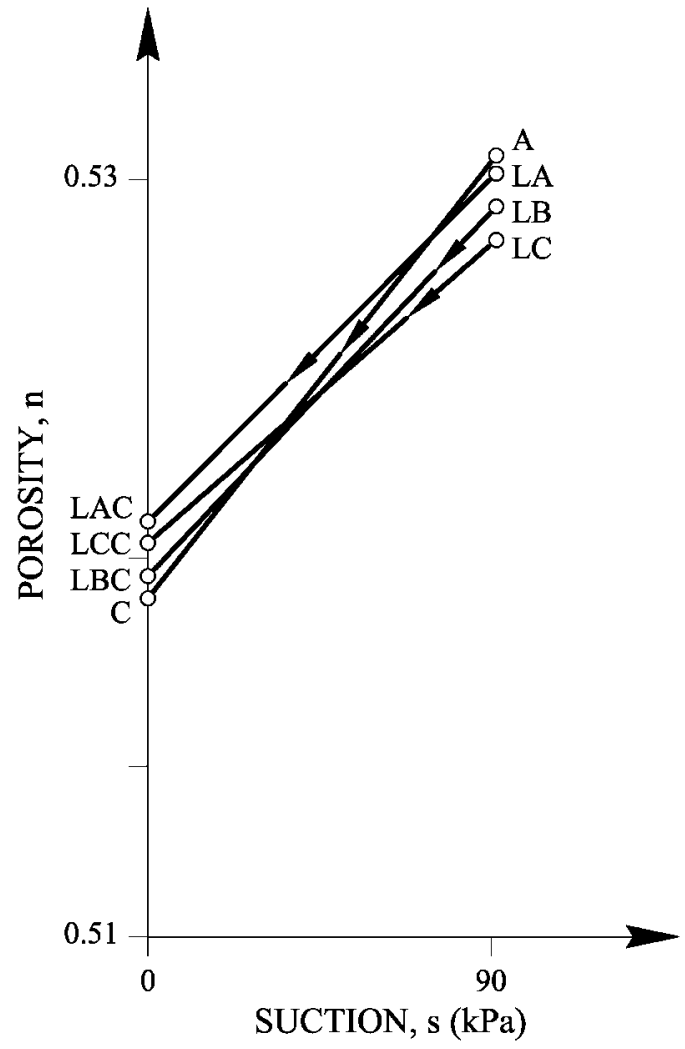

Figure 30. Changes in porosity measured in stress paths shown in Figure 28(a). 


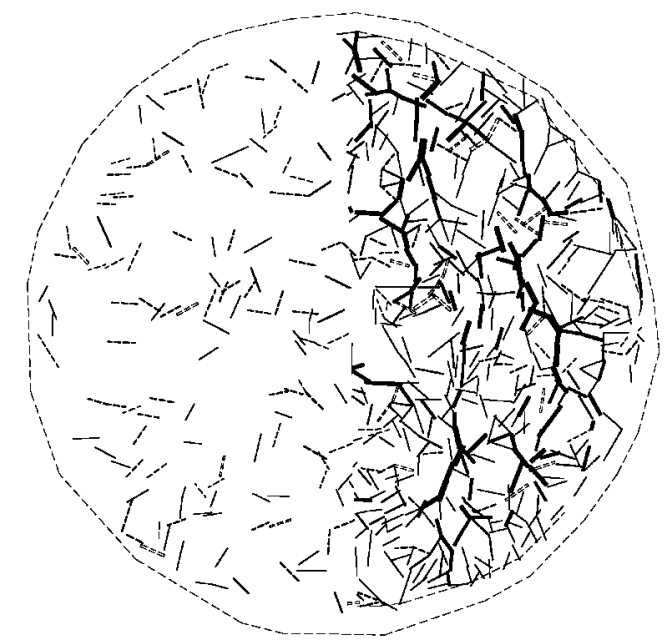

Figure 31. Total forces at the contacts in stress state $\mathrm{LC}\left(\phi_{\mathrm{mov}}=30^{\circ}, s=90 \mathrm{kPa}\right.$, see Figure 28(a)). The left part of the Fig. shows forces at contacts in which a negative force exists.

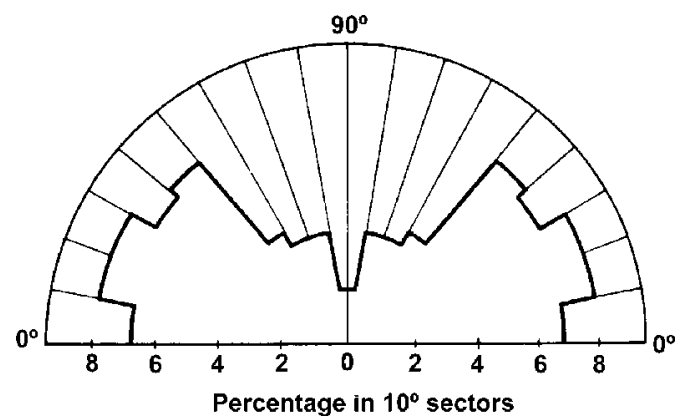

Figure 32. Orientation of capillary forces at contacts when a deviatoric stress $\left(\phi_{\text {mov }}=30^{\circ}\right)$ is applied at constant suction $s=90 \mathrm{kPa}$.

contact force. It may be checked that these capillary forces follow often horizontal or subhorizontal directions. This trend is clearly appreciated in Figure 32, where dominant capillary force orientations have been ordered in a polar diagram. The orientation of these capillary forces, along the minor principal stress, helps to resist the deviatoric stress. Menisci thus play a double role: they contribute to increase the maximum tangential forces at the contacts but they resist also in a direct manner, with a pure tensile force component, the deformations along the minor principal stress.

\section{DETAILS OF MICROSTRUCTURAL INTERACTION}

A more detailed examination of particle configurations and their interaction forces reveals some interesting characteristics of the role played by capillary forces. The cases presented here have been taken from some of the numerical tests presented previously. 
The obliquity of total forces at the contacts should be attributed to a local meniscus action. Since a constant basic friction angle (grain-to-grain) $\phi_{\mathrm{M}}=26.5^{\circ}$ has been selected, every inclination, from the normal direction at the contact, larger than this angle indicates the presence of capillary forces. For instance, in Figure 33, particles 2 and 3 are held stable with just two contacts because of the meniscus acting on both of them.

Capillary forces are able to maintain sets of particles lightly loaded inside the externally moredeveloped force chains, as may be observed in Figure 34. In some cases, menisci act as internal tensors, which may be visualized as inner rubber bands, which contribute to stabilize compression force chains (Figures 35 and 36). Particle 1 in Figure 36, if not for the presence of menisci ' $\mathrm{m}$ ', would probably become unstable. A reduction of capillary suction will tend

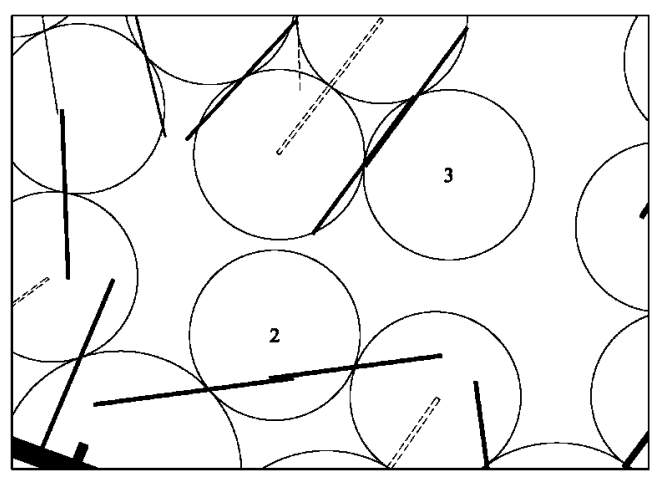

Figure 33. Contact forces of high obliquity.

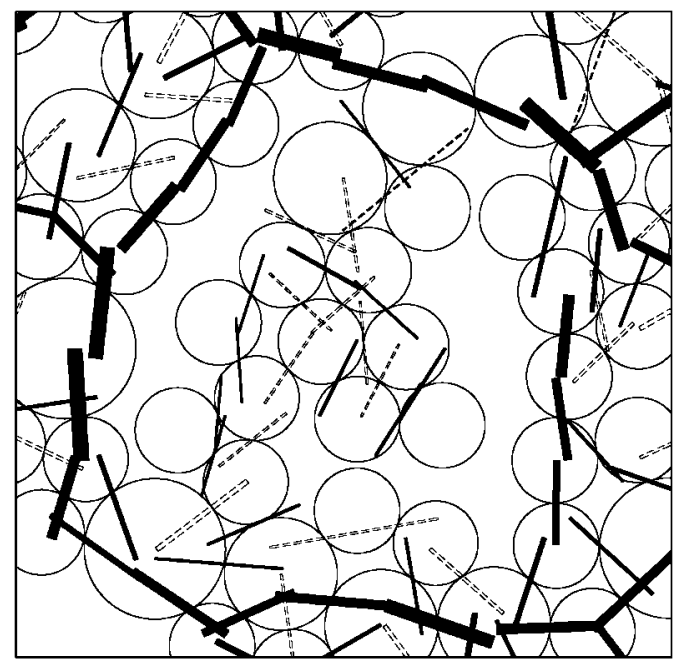

Figure 34. Set of lightly loaded particles inside a ring of highly loaded particles. 


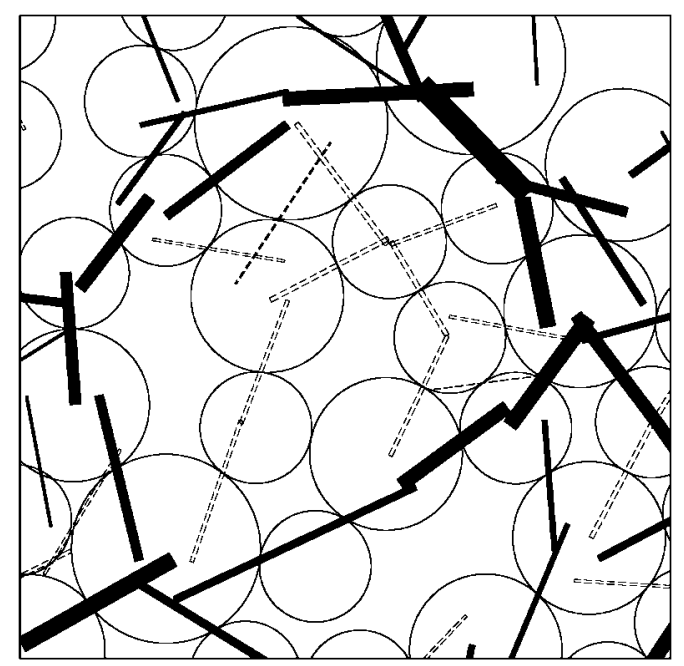

Figure 35. Tensioned particles inside a loaded ring.

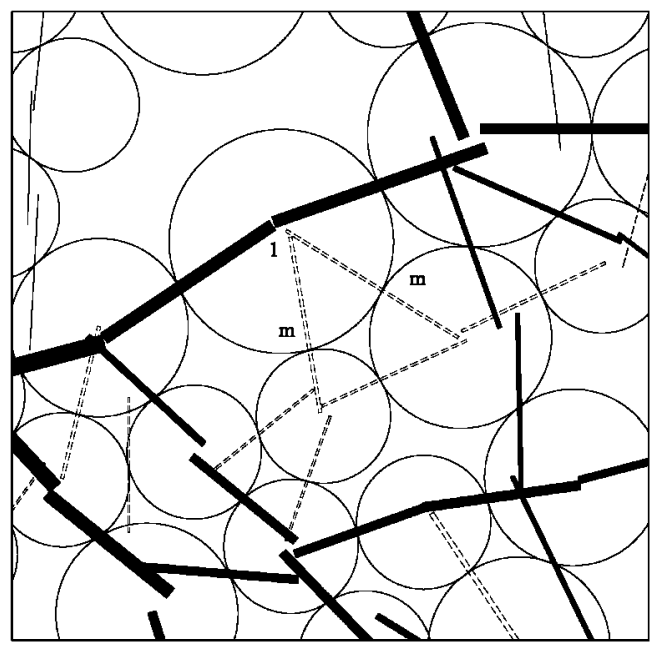

Figure 36. Particle 1 is maintained in a loaded chain as a result of the traction forces induced by menisci 'm'.

therefore to destroy the chain force through particle 1. It has often been observed that menisci contribute to maintain chain forces of 'double thickness': those formed by parallel chains separated by a particle diameter. Figure 37 illustrates this phenomenon. Loss of suction would lead to the destruction of this double chain and to a local rearrangement of particles. 


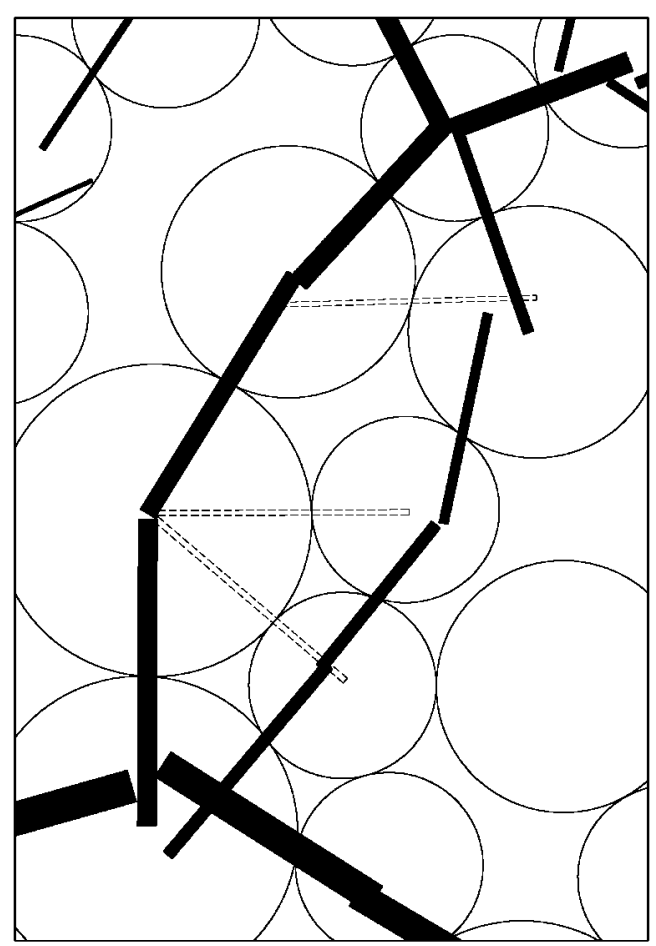

Figure 37. Stabilizing effect of menisci allows the configuration of a double force chain.

\section{CONCLUSIONS}

This paper outlines the fundamental characteristics of a microstructural model for unsaturated granular soils and describes the results of a number of numerical tests. The objective was to contribute to a better understanding of suction effects on deformation mechanisms of unsaturated granular soils. General expressions for the influence of water menisci at the contact between spheres of different diameter as well as transfer laws between pores and menisci have been defined. The numerical model developed for arrangements of spheres was, however, twodimensional since the centres of spheres were assumed to remain in a given plane. The problem was thus made more tractable. A fairly homogeneous 'sample' of silt size was used for the numerical tests presented. Collapse behaviour has been reproduced by the microstructural model developed. It has been shown that the menisci at the grain-to-grain contacts help to maintain stable the force chains that develop in the loaded granular structure. This effect may be described as an internal tensioning, which adds stability and prevents buckling of loaded chains. When suction is reduced, some force chains are destroyed and a rearrangement of the soil structure takes place. This is the nature of wetting-induced collapse.

The numerical model is also able to simulate expansion as a result of suction reduction. Expansion is associated with capillary force relaxation at the grain contacts. It has an underlying elastic nature and its intensity is controlled by mechanical contact properties. In a 
wetting path, a transition between net expansion to compression (collapse) has been reproduced in the numerical model. This behaviour has also been observed in laboratory experiments.

Several isotropic stress paths involving mean stress and suction changes have been simulated in order to investigate some regularity conditions, which have been accepted as hypothesis for macroscopic continuous elastoplastic models developed in recent years. The numerical model developed includes in a natural way some aspects such as large deformations or changes in soil structure as deformation increases, which are difficult to model by macroscopic continuous models. In a particulate model, the dependence of overall behaviour on the stress path seems guaranteed even for stress states, which are identified as elastic in continuum models. This stress path dependence has been observed in all the numerical tests performed.

The application of drying-wetting paths leads to the accumulation of irreversible compressible strains. The granular specimen tested has a collapsible pore structure and every suction cycle results in a rearrangement of soil structure towards a smaller porosity. These results are in qualitative agreement with laboratory results in which clay samples having an open structure were subjected to suction cycles in a suction-controlled cell.

The mechanisms of soil response against deviatoric stress states, at constant suction, have also been investigated. It was found that contact menisci contribute to the soil resistance against shearing by increasing the normal force at the contacts but also in a direct way, resisting in tension the strains along the minor principal stress direction.

In a series of numerical tests, the effect of deviatoric stress ratios on collapse upon wetting has also been investigated. Computed results agree with some reported experiments on a compacted clayey sand. In particular, it was found that volumetric collapse deformations are essentially governed by the applied net mean stress.

It may be finally concluded that the most characteristic features of unsaturated soil behaviour should be attributed to its particulate structure and to capillary effects at the grain-to-grain contacts. Matric or capillary suction is, therefore, the relevant component of suction able to explain mechanical effects in unsaturated soils in which its granular nature dominates soil behaviour.

\section{REFERENCES}

1. Cundall PA, Strack ODL. A discrete numerical model for granular assemblies. Géotechnique 1979; $29(1): 47-65$.

2. Cundall PA, Strack ODL. The development of constitutive laws for soil using the Distinct Element Method. Proceedings of the ICONMIG 1979; 289-298.

3. Cundall PA, Drescher A, Strack ODL. Numerical experiments on granular assemblies; measurements and observations. Proceedings of the IUTAM Conference on Deformation and Failure of Granular Materials 1982; 355-370.

4. Campbell CS, Brennen CE. Computer simulation of chute flows of granular materials. Proceedings of the IUTAM Conference On Deformation and Failure of Granular Materials 1982; 515-521.

5. Campbell CS, Brennen CE. Computer simulation of shear flows of granular material. In Mechanics of Granular Materials. Campbell CS, Satake M. eds. Elsevier: New York, 1983; 313-326.

6. Walton OR. Explicit particle dynamics model for granular materials. Proceedings of the 4th International Conference on Numerical Methods in Geomechanics, Elsevier: Edmonton, 1982; 1261-1268.

7. Walton OR. Particle-dynamics calculations of shear flow. In Mechanics of Granular Materials. Campbell CS, Satake M. eds. Elsevier: New York, 1983; 327-338.

8. Williams JR. A method for three dimensional dynamic contact analysis of numerous deformable discrete bodies including automatic fracturing. Proceedings of the International Conference Computational Plasticity, Elsevier: Barcelona, 1987; 1177-1202.

9. Scott RF. Failure. Géotechnique 1987; 37(4):423-466.

10. Cundall PA. Numerical experiments on localization in frictional materials. Ingenieur Archive 1988; 59: $148-159$. 
11. Zhai ED, Miyajima M, Kitamura M. DEM simulation of rise of excess pore water pressure of saturated sands under vertical ground motion. In Computer Methods and Advances in Geomechanics, vol. 1. Yuan J-X. ed. Balkema: Rotterdam, 1997; 1: 535-542.

12. Gili JA. Modelo microestructural para medios granulares no saturados. Ph.D. Thesis UPC: Barcelona, 1988.

13. Dorsey NE. Properties of ordinary water substance. American Chemical Society Monograph Series 1968; 81: 673.

14. Kovacs G. Seepage Hydraulics. Development in Water Science. Elsevier: Amsterdam; 1981, 730pp.

15. Matyas EL, Radhakrishna HS. Volume change characteristics of partially saturated soils. Géotechnique 1968; 18(4): $432-448$.

16. Lloret A, Alonso EE. State surfaces for partially saturated soils. Proceedings of the 11th ICSMFE, vol. 1/A/35, Balkema: San Francisco, 1989; 557-562.

17. Fredlund AG, Rahardjo H. Soil mechanics for unsaturated soils. Wiley: New York, 1993.

18. Alonso E, Gens A, Hight DW. Special problem Soils. General Report. Proceedings of the 9th ECSMFE, vol. $3,1987$. $1087-1146$.

19. Alonso E, Gens A, Josa A. A constitutive model for partially saturated soils. Géotechnique 1990; 40(3): 405-430.

20. Wheeler SJ, Sivakumar V. An elastoplastic critical state framework for unsaturated soil. Géotechnique 1995; 45(1): $35-53$.

21. Cui YJ, Delage P, Sultan N. An elastoplastic model for compacted soils. In Unsaturated Soils/Sols Non Saturés. Presses des Ponts et Chaussées, vol. 2. Alonso EE, Delage P. eds. Balkema: Rotterdam, 1995; 703-709.

22. Alonso E, Yang DQ, Lloret A, Gens A. Experimental behaviour of highly expansive double-structure clay. In Unsaturated Soils/Sols Non Saturés. Presses des Ponts et Chaussées, vol. 1. Alonso EE, Delage P. eds. Balkema: Rotterdam, 1995; 11-16.

23. Lawton EC, Fragaszy RJ, Hardcastle JH. Stress ratio effects on collapse of compacted clayey sand. Journal of Geotechnical Engineering ASCE 1991; 117(5):714-730.

24. Alonso E, Josa A, Gens A. In Modelling the Behaviour of Compacted Soils upon Wetting. Raul J. Marsal (ed.). Soc. Mexicana de Mecánica de Suelos: A.C. México, 1992; 207-223.

25. Erol DA, El-Ruwai JA. Collapse of desert loess. Proceedings of the 4th Congress on IAEG, vol. 1, Balkema: Amsterdam, 1982; 443-448. 